DOE/NASA/0097 80/1

NASA CR-165218

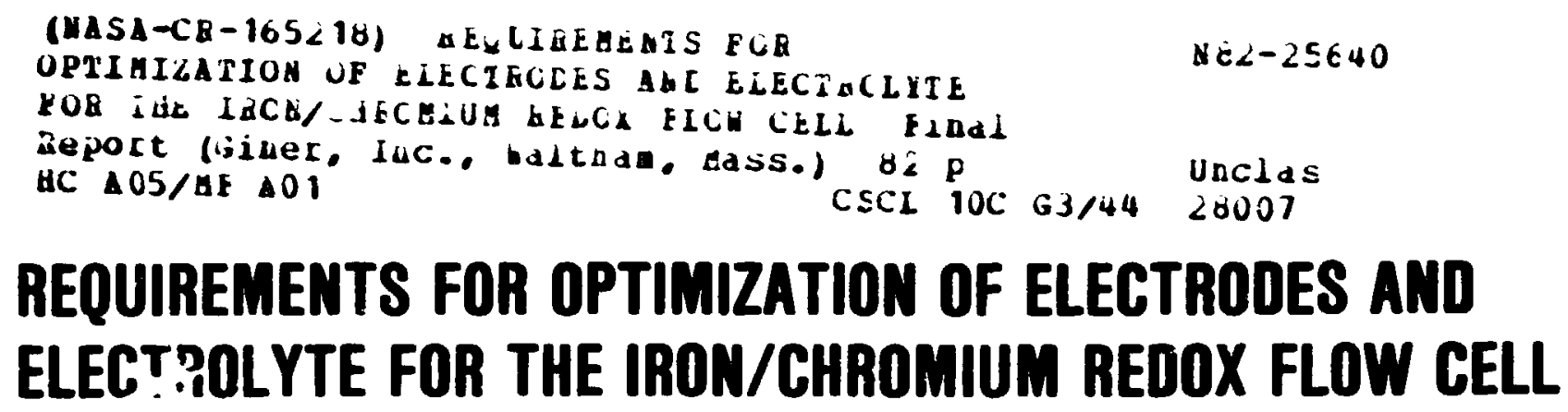

Virtod Jalan

Herbert Stark

Jose Giner

GINER, INC.

14 Spring Street

Waltham, Massachusetts 02154

SEPTEMBER 1981

Prepared for NATIONAL AERONAUTICS AND SPACE ADMINIS THON Lewis Research Center Under Contract DEN3-97

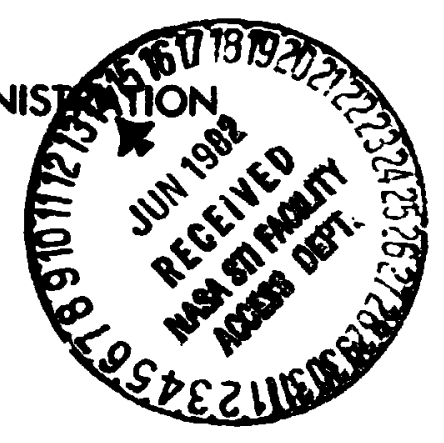

for

U. S. DEPARTMENT OF EMERGY ENERGY TECHNOLOGY ENERGY STORAGE SYSTEMS DIVISION 


\section{REQUIREMENTS FOR OPTIMIZATION OF ELECTRODES AND ELECTROLYTE FOR THE IRON/CHROMIUM REDOX FLOW CELL}

Vinod Jalan

Herbert Stark

Jose Gii er

GINER, INC.

14 Spring Street

Walthom, Massachusetts 02154

SEPTEMBER 1981

Prepared for

NATIONAL AERONAUTICS ANC SPACE ADMINISTRATION

Lewis Research Center

Clevel and, Ohio $\mathbf{4 4 1 3 5}$

Under Contract DEN3-97

for

U. S. DEPARTMENT OF ENE::GY

ENERG ? TECHNOLOGY

ENERGY STORAGE SYSTEMS OIVISION

Washingron, D.C. 20545

Under interacency Agreement DE-A I-04-80-AL-12726 
ABSTRACT

EXECUTIVE SUMMARY

Page No.

I. INTROOUCTION

II. OVERVIEW OF PREVIOUS WORK

A. Solubility of $\mathrm{CrCl}_{2}$ and $\mathrm{CrCl}_{3}$ in $\mathrm{HCl}$

vii

viii

B. Stability of Chromous ion

C. Electrode Material Evaluation

III. THE EFFECT OF ELECTROLYTE IMPURITIES ON THE $\mathrm{Cr}(111) / \mathrm{Cr}(\mathrm{II})$ REDOX REACTION

A. The Effect of $\mathrm{Fe}$ (II) on the Retuction of $\mathrm{Cr}$ (III) at a $\mathrm{Au} / \mathrm{Pb}$ Codeposited Electrode

B. The Effect of Al(III) on the Reduction of $\mathrm{Cr}$ (III) at a $\mathrm{Au} / \mathrm{Pb}$ Codeposited Electrode

C. Comparison of Fisher and McGeon Chromic Chloride Solutions

IV. INVESTIGATION OF THE COMPLETE Fe/Cr REDOX SUBSCALE CELL 12

A. Subscale Description 12

B. Polarization Measurements in Complete Cell 14

V. INVESTIGATION OF ELECTRODE PREPARATION PROCEDURES 17

A. Physical Characterization 17

B. Activation by "Standard" Procedure 20

C. Electrochemical Screening of Felts Activated by Standard Procedures

D. Improved Catalyzation Processes

VI. INVESTIGATION OF THE Cr(III)/Cr(II) REDOX REACTION BY CYCLIC VOLTAMMETRY

A. Hyorogen Evolution and $\mathrm{Pb}$ Deposition on Carbon 38

8. Hydrogen Evolution and $\mathrm{Pb}$ Deposition on $\mathrm{Au}$ on Carbon 38

C. Chromic Chloride Reduction on $\mathrm{C}, \mathrm{Pb}$, and $\mathrm{Au} / \mathrm{Pb}$

VII. BISMUTH: AN ALTERNATE ELECTROCATALYST FOR $\mathrm{Cr}$ (III)/Cr(II) 49

A. Stability 49

B. Gismuth on Carbon Electrode 49

C. Gold/Bismuth Electrode 51

VIII. SIGNIFICANT RESULTS AND CONCLLSIONS 54

IX. RECOMMENDATIONS FOR FUTURE :SORK

$X$. REFERENCES 61 
Page No.

XI. APPENDICES

A. Standard Thermal Gold Plating Method

63

B. Alcohol Assisted Gold Deposition Method for

64 Making Felt Electrodes 


\section{LIST OF TABLES}

Table

Title

Page

IV-1 Redox Cell Testing

15

IV-2 Cell Polarization

V-1 Physicai Properties of Felts "as Received"

19

$v-2$

$\mathrm{H}_{2}$ Evolution on Carbon Felts at Each Stage of Standard Activation Procedure

VIII-1 Roles of $\mathrm{C}, \mathrm{Au}$ and $\mathrm{Fb}$ on $\mathrm{Cr}$ (III)/Cr(II) Reactions 
Figure

Page

S-1 Hydrogen Evolution and $\mathrm{Cr}$ (III) Reduction on Three Carbon

Felts after Standard Activation ix

S-2 Progressive Improvements in the Catalyzation Techniques $\mathrm{H}_{2}$ Evolution Characteristics of $8 / 79$ Felts $x i$

S-3 Cyclic Voltamogram of $\mathrm{Cr}$ (III)/Cr(II) Reaction at Lead $\quad x i$

S-4 Cyclic Voltammogram of Lead Deposition-Dissolution at Gold xiv

S-5 Cyclic Voltammogram of $\mathrm{Cr}$ (III)/Cr(II) Reaction at Gold/Lead xv

I I-1 Chromous Chloride Solubility in $\mathrm{HCl} \quad 3$

II-2 Chromic Chloride/Chromous Chloride Redox Characterization of $\mathrm{Au} / \mathrm{Pb} 5$

III-I Effect of $\mathrm{Fe}$ (II) Upon $\mathrm{Cr}$ (III) Reduction at Au/Pb 7

III-2 Effect of Al(III) Upon $\mathrm{Cr}$ (III) Reduction at $\mathrm{Au} / \mathrm{Pb} \quad 9$

$\begin{array}{lll}\text { II -3 Electrochemical Behavior of Fisher and McGeon Chromium } & \\ \text { Chloride Electrolytes } & 10\end{array}$

III-4 Performance Comparison of Reagent Grade and Technical
Grade Chromium Chloride

IV-1 Subscale Flow Cell System 13

V-1 Half-Cell Configuration 22

V-2 Hydrogen Evolution and $\mathrm{Cr}$ (III) Reduction on Bare Carbon Felt 26

V-3 Hydrogen Evolution and $\mathrm{Cr}$ (III) Reduction After Standard Activation of Carbon Felt $\quad 27$

V-4 Comparison of Three Carbon Felts 28

V-5 Comparison of Carbon and Graphite Felts 30

V-6 Effects of $\mathrm{HNO}_{3}$ Normalization Treatment

V-7 Effects of Alcohol Assisted Gold Impregnation 34

V-8 Progressive Improvements in the Catalyzation Techniques 35

VI-1 Cyclic Voltammogram of Lead Deposition-Dissolution Reaction
at Carbon Felt

VI-2 Hydrogen Evolution at Gold on Carbon Felt 40

VI-3 Multi-Cycle Voltamogram of Lead Deposition-Dissolution
Reaction at Gold on Carbon 
Figure

Page

VI-4 Cyclic Voltarmogram of $\mathrm{Cr}$ (III)/Cr(II) Reaction on Bare Carbon

VI-5 Cyclic Voltarmogram of $\mathrm{Cr}$ (III)/Cr(II) Reaction at Lead

VI-6 Steady State Cyclic Voltamogram of $\mathrm{Cr}$ (III)/Cr(II) Reaction at Lead/Gold

VI-7 Multi-Cycle Voltammogram of $\mathrm{Cr}$ (III)/Cr(II) Reaction at Gold/Lead

VII-1 Stability of Bismuth and Lead Electrocatalysts

VII-2 Hydrogen Evolution and $\mathrm{Cr}$ (III) Reduction, With $\mathrm{PbCl}_{2}$ and With $\mathrm{BiCl}_{3}$

VII-3 Cyclic Voltamogram of $\mathrm{Cr}$ (III)/Cr(II) Reaction at Au/Bi . 53

VIII-1 Baseline Activation Procedure 
With the recent technological developments, the iron/chromium redox flow cell has become an attractive system for bulk eneray storage application. Earlier investigations at Giner, Inc. had established that the solubility and stability of aqueous acidic solution of $\mathrm{Cr}$ (II) and $\mathrm{Cr}$ (III) chlorides are sufficient for redox applications and had resulted in a number of findings which have enhanced the attractiveness of the $\mathrm{Cr}$ (III)/Cr(II) vs. Fe(III)/Fe(II) redox cell. The Giner, Inc. discovered gold/lead combination electrocatalyst has proved to be the on?y system to date that provides both high activity for the CrIII/CrII redox reaction and very high hydrogen overvoltage. A combination of gold and lead deposited on a porous carbon felt structure provided a practical electrode for the $\mathrm{Cr}$ side for the redox flow cell.

A study to characterize different felt materials revealed that the difficulties encountered by NASA with application of electrocatalyst to a batch of carbon felt material were caused by non-reproducibility of the vendor supplied felt, mostly with respect to tis gold uptake capabilities. We found that a normalization treatment precleaning the "poor" substrate material with dilute nitric acid - in conjunction with the use of very dilute gold chloride solutions, produced substantial imnrovements.

Improved catalyzation techniques were developed that included a pretreatment of carbon substrates and provided a "normalized" carbon surface for uniform gold deposition. This permitted efficient use of the different batches of carbon felt materials which initially vary significantly in their physical and surface chemical properties, as well as their electrochemical behavior. Further modification (an alcohol assisted method) of the gold impregnation technique gave further improvement and to date the best performing electrodes.

In addition to linear sweep voltammetry, cyclic voltammetry has been used to determine the effects of different activation procedures on the $\mathrm{Cr}(I I I) / \mathrm{Cr}$ (II) redox and hydrogen evolution reactions. Attempts are made to identify the roles of carbon, gold, and lead in the overall redox cycle. The behavior of the electrodes at both normal battery operating potentials and more extreme potentials is discussed with the implications for preparing efficient and stable electrodes for the energy storage battery. 


\section{EXECUTIVE SUMMARY}

The redox flow cell program at Giner, Inc. prior to this study resulted in a number of findings which enhanced the attractiveness of the $\mathrm{Cr}$ (III)/ $\mathrm{Cr}$ (II) vs. Fe(III)/ Fe(II) redox cell as an energy storage concept; in particular the discovery that small quantities of lead and gold added to the chromium electrone can substantially improve the behavior of this electrode. Both gold and lead act as catalysts for the chromium reaction. An additional function of the lead is to mi.:imizo hydrogen evo ion by covering the gold surface during charging, since Au has low hydroger. overvoltage and $\mathrm{Pb}$ high overvoltage. Some fraction of the lead may deplate during discharge but it replates upon charge. Silver and copper can replace the gold, but are not as satisfactory.

This electrocatalyst combination was applied by MASA-LeRC to porous electrodes made of carbon felt. After initial success it was discovered at IASA that a new batch of carbon felt supplied by the same vendor (Fiber Materials, Inc.) displayed significant hydrogen evolution and evidence of improper catalyzation. A comparison of three batches of carbon felts catalyzed by the impregnation/thermal decomposition technique is shown in Figure S-1. Clearly there were large differences in hydrogen evolution currents; the chromium reduction currents remained about the same.

Characterization of difterent carbon felt materials revealed sign icicant differences in their physical and surface chemical properties. The most signigicant difference was found to be the extent of gold pick up by different felts from an aqueous

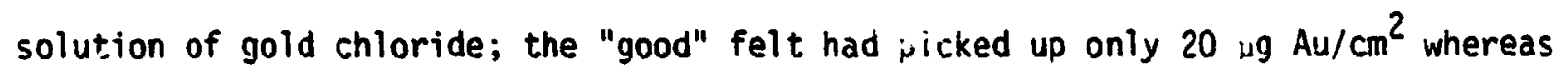
the "poor" feit exhausted the solution picking up gold which amounted to about 60 $u g \mathrm{Au} / \mathrm{cm}^{2}$.

He believed that the increased gold take up was due to excessive reducing groups on the surface of the $8 / 79$ poor carbon felts. A dilute nitric acid soak, as a precleaning step, was used to oxidize the reducina arouos. Such a treatment in 


\section{ORICINAL PACE IS \\ OF POOR QUALTY}

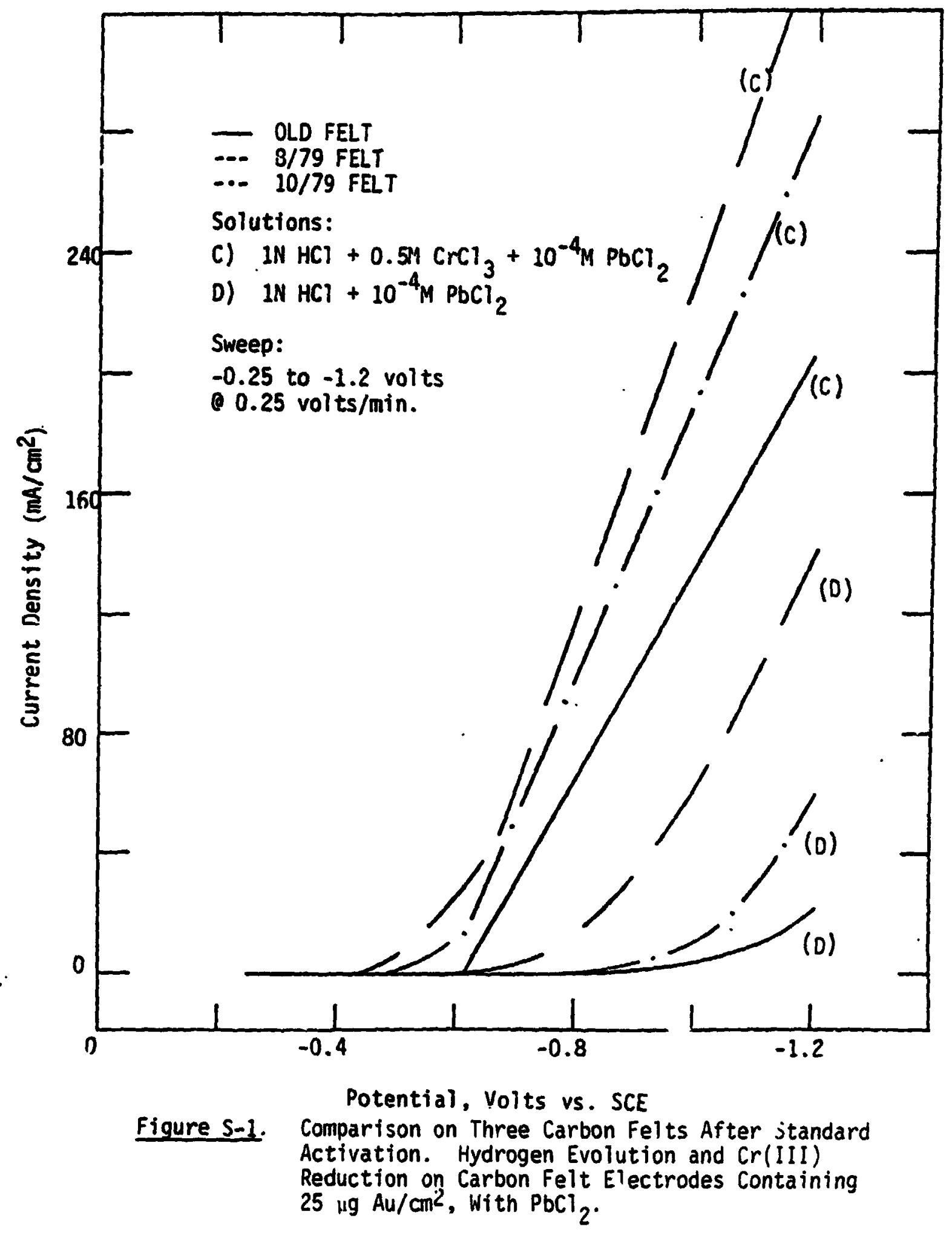


conjunction with the use of a dilute gold solution for impregnation gave significant improvement in the periormance. Further improvements in the electrode performance were realized by an alcohol-assisted imoregnation technique combined with a precleaning step using $\mathrm{KOH}$. These improvements were validated by full cell tests at NACA. LeRC and shown in Figure S-2.

In order to optimize this electrode system and to establish long term stability of these electrodes. it was necessary to identify the roles of carbon, gold and lead for the $\mathrm{Cr}$ (III)/Cr(II) redox reaction. For this purpose we used cyclic voltammetry techniques.

Carbon: Very little $\mathrm{H}_{2}$ evolution was observed on plain carbon felt in $\mathrm{HCl}$. A plain $\mathrm{fe}^{\prime} \mathrm{t}$ electrode was then cycled in $0.2 \mathrm{M} \mathrm{Cr}$ (III) solution. Very small amounts of $\mathrm{Cr}$ (III) were reduced. Essentially no $r$ (II) was oxidized in the practical range of battery operation. At very high polarizations, however, $\mathrm{Cr}(I I)$ did oxidize on carbon, but in a complex manner which is not understood. The multiple peaks are probably due to the inhomogeneous surface of carbon felt (Figure S-3).

Lead: Lead deposition-dissolution was studied by introduction of $\mathrm{PbCl}$ to an $\mathrm{HCl}$ solution. Very clean deposition and dissolution peaks were observed. We found a complete absence of reactions at higher potentials indicating that nu under potential deposited (UPD) lead is formed on carbon felt. This electrolyte was made 0.2H in Cr(III). The resulting voltammogram is shown in Figure S-3. At $-600 \mathrm{mV}$, coincident with lead deposition, we saw large amounts of $\mathrm{Cr}$ (III) reduction. This very clearly established that bulk lead is an active catalyst for chronium reduction. Essentially reversible oxidation of chromium occurred on the lead surface but coincident with lead dissolution there was a precipitous drop in the chromium oxidation reaction. Carbon is totally inactive for $\mathrm{Cr}([\mathrm{i})$ oxidation at this potenital. At higher overvoltages once again chromium oxidation proceeded in a complex manner. The essential features of chromium oxidation peaks in this higher potential range remained the same as that on plain carbon felt. 


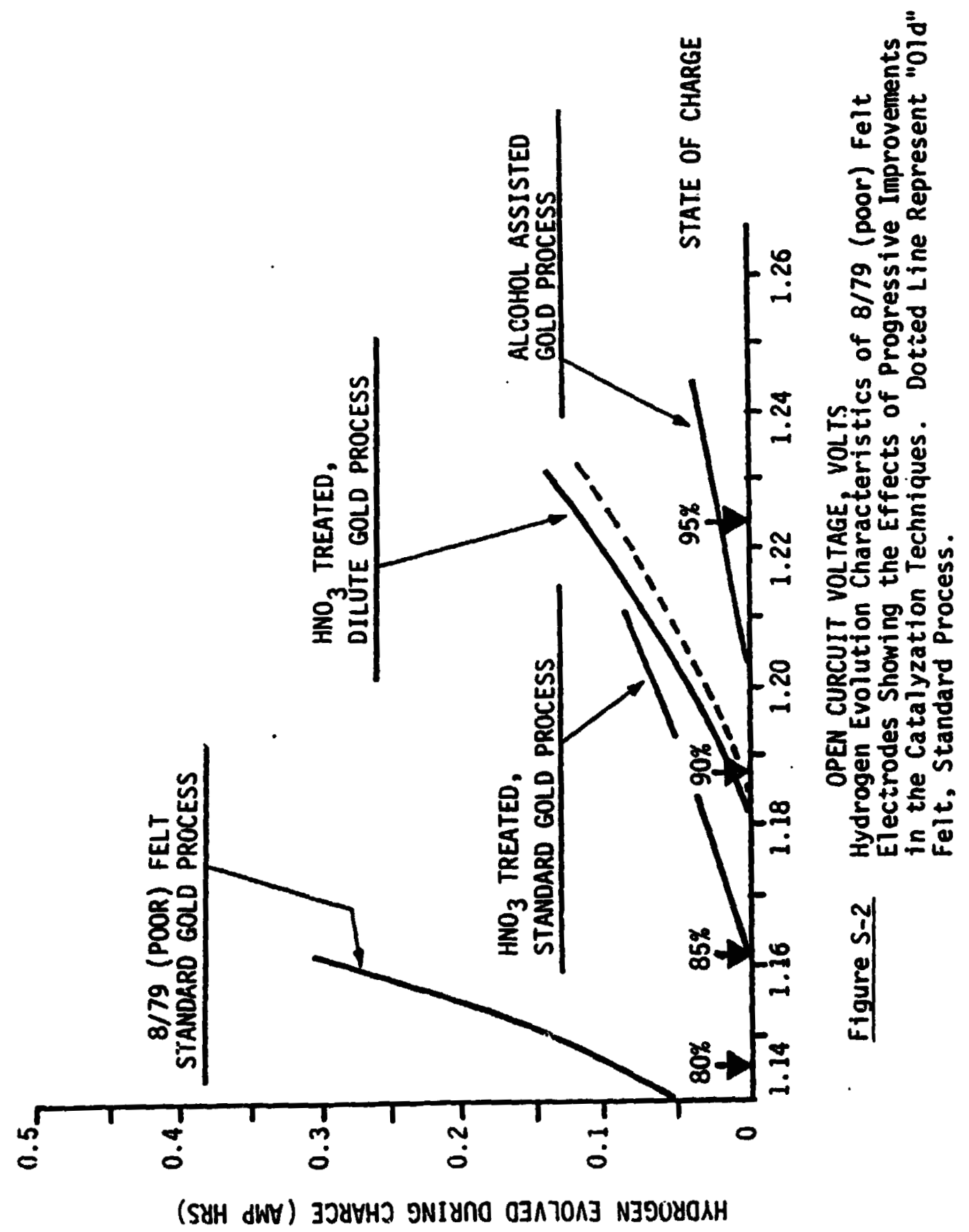




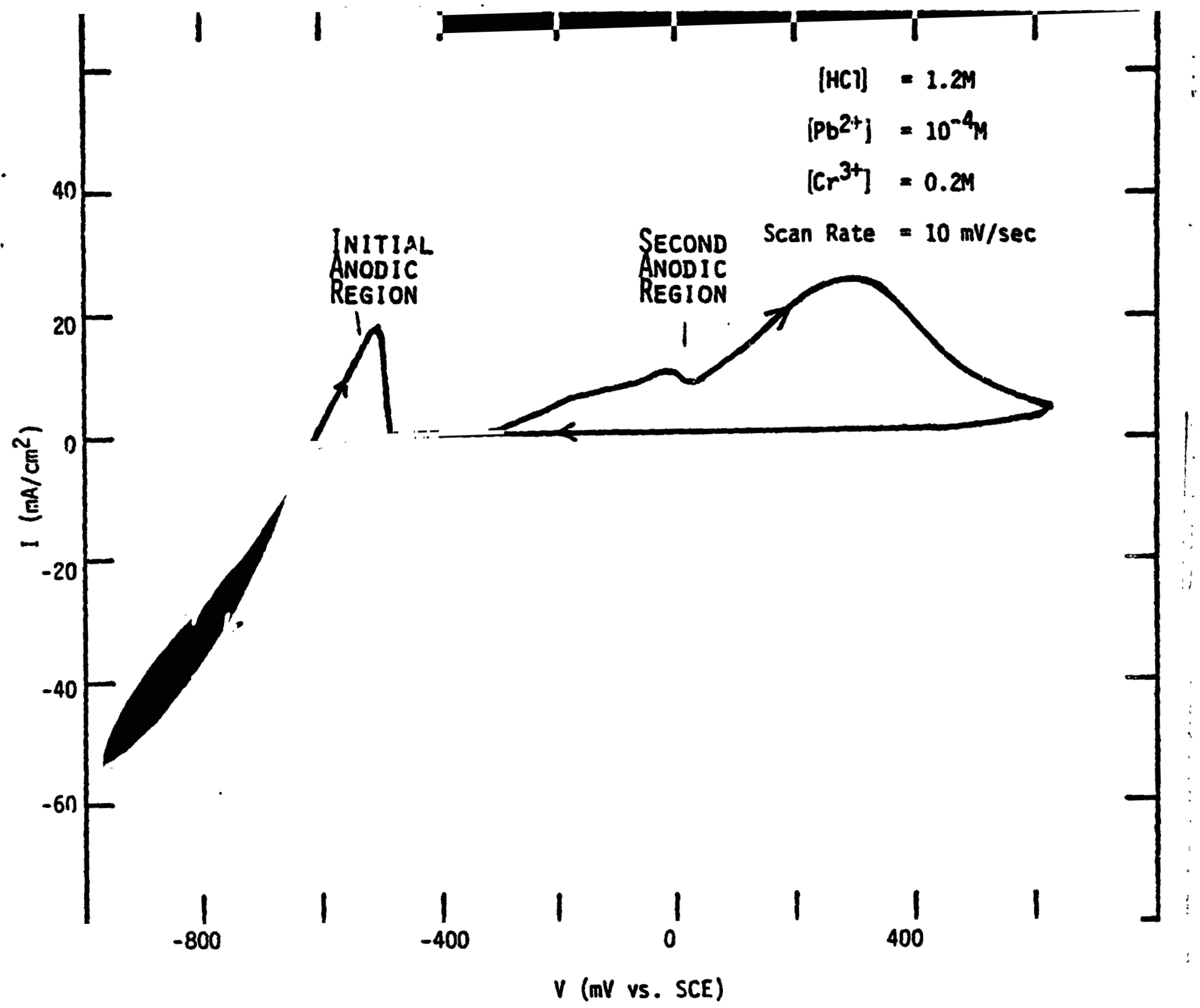

Figure S-3: Steady State Voltamnogram of $\mathrm{Cr}$ (III)/Cr(II) Reaction at Lead on Carbon Felt Electrode. 
Gold: As expected, the hydrogen evulution reaction on a clean gold-on-carbon felt is substantial. As before $\mathrm{Pb}$ (II) ions were introduced into the electrolyte by adding a small volume of concentrated lead chloride solution. The interesting portion of the voltanmogram is shown in figure S-4. As expected, the hydrogen evolution was reduced. The deposition-dissolution reaction of lead was resolved from hydrogen evolution reaction so that some correlation of the lead deposition and hydrogen evolution reactions can be made. It is important to note that as successive cycles are performed, the amount of lead deposited decreased, but the hydrogen evolution reaction is unchanged. Results are presented to show that very small amounts of lead corresponding to monolayer or aven submonolayer coverage of go? I are sufficient to effect large decreases in hydrogen evolution.

Figure $\mathrm{S}-5$ is a multicycie voltarmogram of $\mathrm{Cr}$ (III)/HCl electrolyte obtained subsequent to holding the potential of the working electrode at $-620 \mathrm{mV}$ for a short time. The current at certain potentials is seen to decrease slightly on : uccessive cycles. Note that on each cycle, the dissolution potential of lead is exceecied. Nevertheless, extended cycling experiments (> 200 cycles) showed that al though subtle changes in electrode behavior are possible, the ability of gcid/lead an carbon felt electrodes to reduce $\mathrm{Cr}(\mathrm{III})$ and oxidize $\mathrm{Cr}(\mathrm{II})$ is maintained.

In summary, techniques have been developed for depositing very small quantities of gold $\left(213 \mu \mathrm{g} \mathrm{Au} / \mathrm{cm}^{2}\right)$ and lead $\left(2100 \mu \mathrm{g} \mathrm{Pb} / \mathrm{cm}^{2}\right)$ on porous sarbon felt so as to yield efficient and stable chromium electrodes. The optimization of these electrodes requires further investigation of: (a) variations in carbon/graphite felts, (b) optimization of gold and lead loadings, and (c) "fine tuning" of catalyzation process. Investigations of multiple peaks on the oxidation portion of cyclic voltammetry and and the electrochemistry of chloride complexes of $\mathrm{Cr}$ (III) also deserve further attention and are expected to contribute to optimization of the chromium electrodes.

In addition to the electrode optimization program, studies at Giner, Inc. included investigations of: (a) performance characteristics in a complete cell, (b) effect of electrolyte impurities on chromium electrode, and (c) bismuth as an al ternate catalyst. 


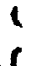

ORIGINAL PAGE IS

OF POOR QuALTY

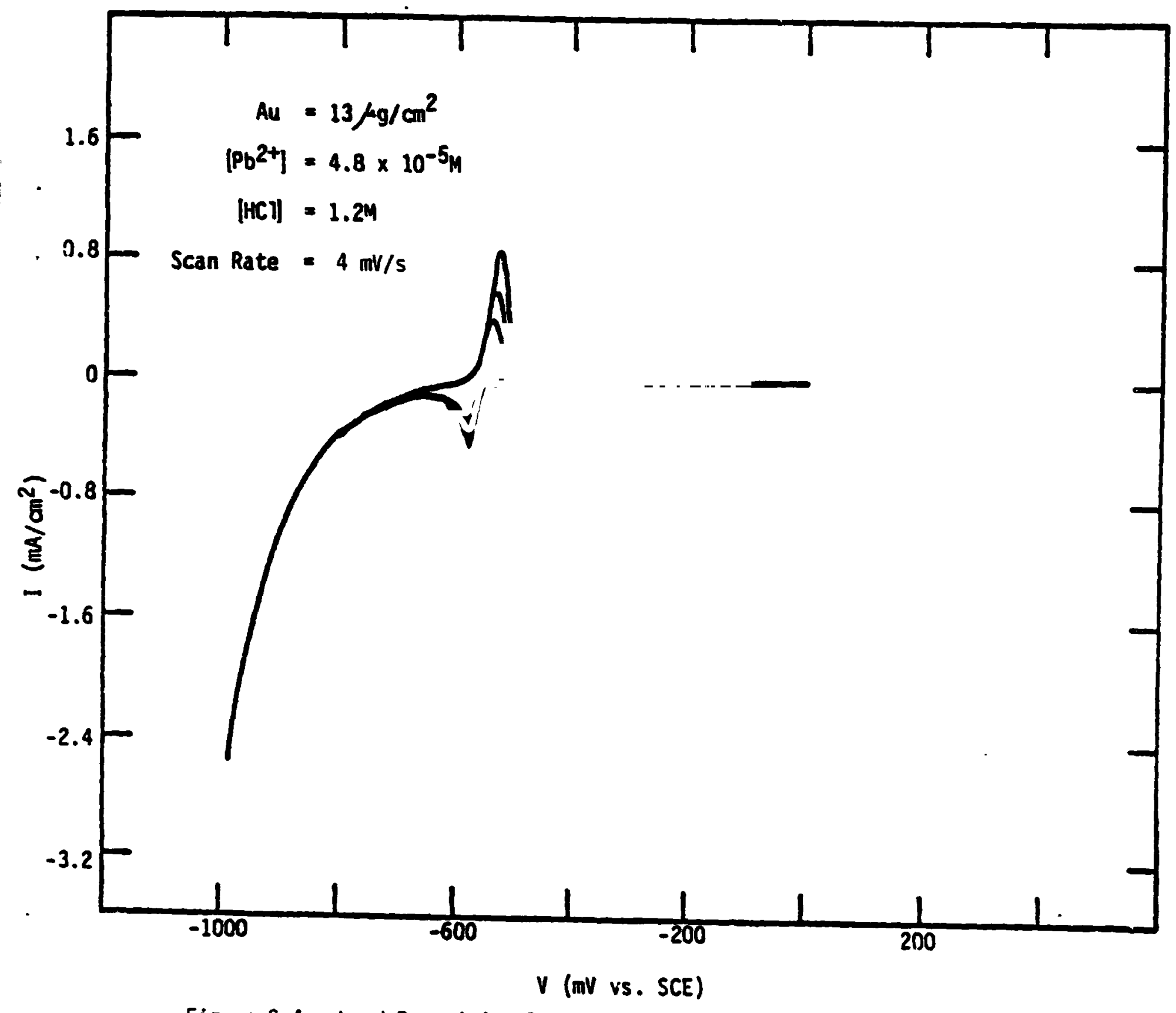

Figure S-4: Lead Deposition-Dissolution at Gold on Carbon Felt. 


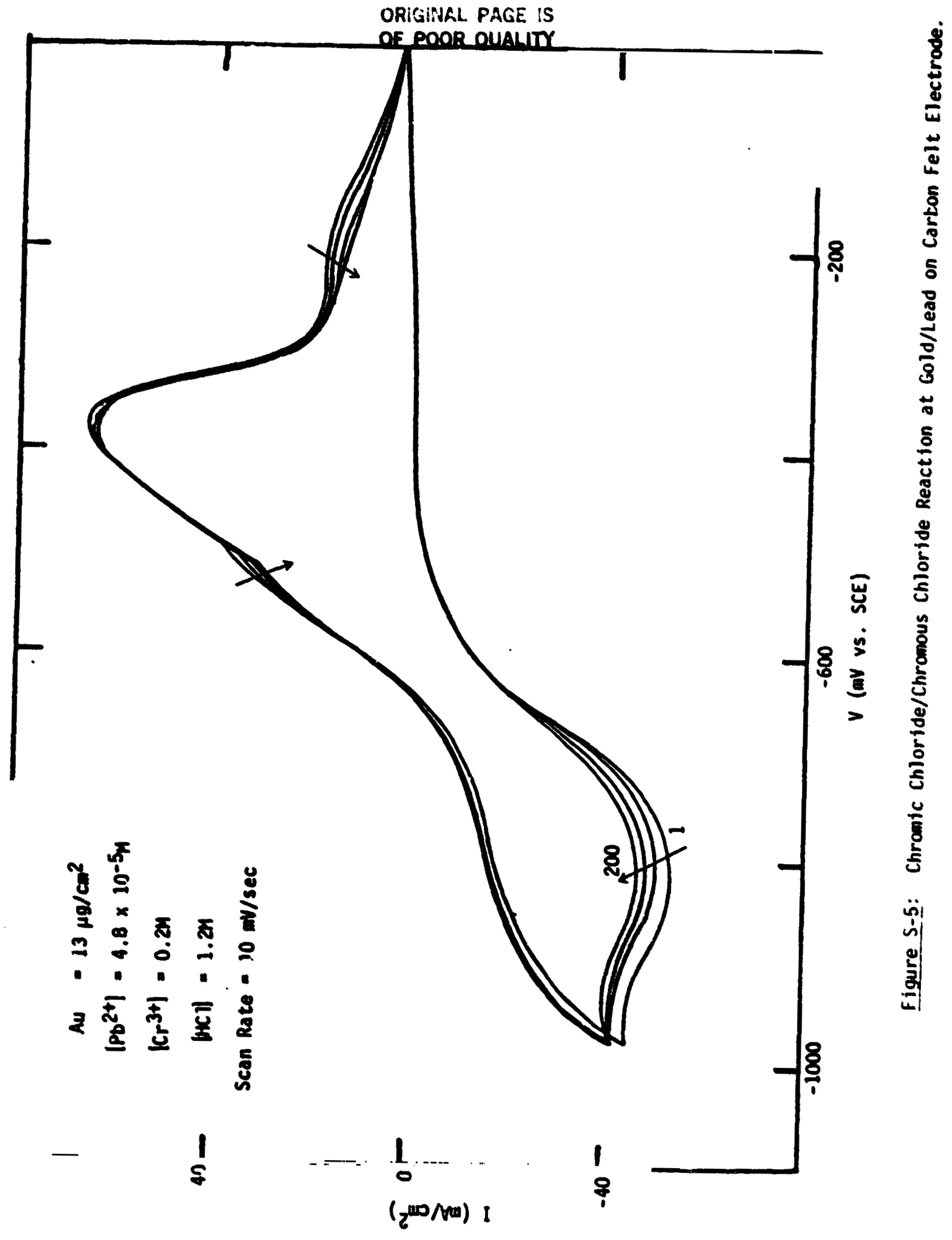


1. INTRODUCTION

MASA Redox systems are electrochenical storage devices that use two fully soluble redox couples as active electrode materials, separated by a highly selective ion exchange membrane. The reactants are contained in large storage tanks and pumped through a stack of redox flow cells where the electrochemical reactions (reduction and oxidation) take place at porous carbon felt electrodes. The redox couples currently under investigation are acidified chloride solutions of chrimium $\left(\mathrm{CrIII/C-II)}\right.$ and iron (FeII/FeIII) ${ }^{(1,2)}$.

Over the past three years ${ }^{(3-7)}$, Giner, Inc. under MASA contracts has carried out investigations of electrodes and electrolyte for the iron/chromium redox system. The solubility and the stability of acidic solutions of chromium chloride were found adequate. The requirement of rapid rates of the electrode reactions is met satisfactorily on the iron side by having electrodes of bare carbon felt. However, a catalyst is needed on the chromium side to increase the rate of chromium reaction. The catalyst must also have a high overvoltage for hydrogen evolution, since thermodynamically, hydrogen is evolved more easily than chromium (III) is reduced. Appreciable co-evolution of hydrogen not only reduces the current efficiency, but over the course of many cycles, would allow the system to get out of balance and thus lose effective capacity. Giner and Canil1 $(4,5)$ found that trace amounts of gold and lead $\left(12-25 \mu \mathrm{g} 4 \mathrm{u} / \mathrm{cm}^{2}\right.$ and $\left.100-200 \mu \mathrm{gb} / \mathrm{cm}^{2}\right)$ would meet these requirements. This is understandable since lead metal has long been known as an effective catalyst for the reduction of $\mathrm{Cr}(I I I)$. The presence of trace amounts of gold seems to be necessary to produce a surface on which the lead plates (or adsorbs) uniformly during the charging cycle. The gold/lead catalyst also greatly improves the discharne rate of the cell compared to the use of lead alone.

A study was continued to further develop and optimize the chromium electrodes and contribute towards commercialization of the NASA iron/chromium redox storage system. 


\section{OVERVIEU OF PREVIOUS WORK}

The primary objective of the prior research program $(3,4)$ was to contribute to the development of the redox flow cell by investigating the major suspected problems of the chromium electrode. These relate to: solubility of reactants, the stability of chromium (II) ions in solution, and the efficient electrocatalysis of the chromium (III) - chromium (II) reaction.

A. Solubility of Chromous Chloride and Chromic Chloride in Hydrochloric Acid Concentrated solutions of chromous and chromic chloride in hydrochloric acid are required to maintain high power density and to hold redox flow system costs at a reasonably low level. Our laboratory work and work by Lux and IIIman ( 8 ) presented in Figure II-1 confirm that solutions up to 3 molar in chromous chloride could be prepared in up to 2.5 molar HCl and establish the suitability for redox battery operation. We found that at high HCl concentration the solubility of chromous chloride dropped significantly.

There is general agreement that acidic chromic chlorides are soluble enough for rec.., battery operation and our results on equilibrium solubility of chromic. chloride confirm that solutions up to 2.5 molar in chromic chloride could be prepared in up to 6 molar $\mathrm{HCl}$.

\section{Stability of Chromous Ion:}

Tne long term stability of the aqueous chromous ion was of concern becau: . thermodynamically it is unstable at low pH; and, at iow $\mathrm{pH}$, chromous ions ould possibly be oxidized by $\mathrm{H}^{+}$and cause seif discharae. Lona term ( $2600 \mathrm{hrs.}$ ) stability of chromous chloride solutions was evaluated and we found that the thermodynamically feasible direct oxidation of chromous ions by hydrogen ions is kinetically inhibised. The stability of chromous chloride was also evaluated in the presence Q. lead and bismuth (in anticipation of their catalytic attractiveness) and no acverse effect was observed. 


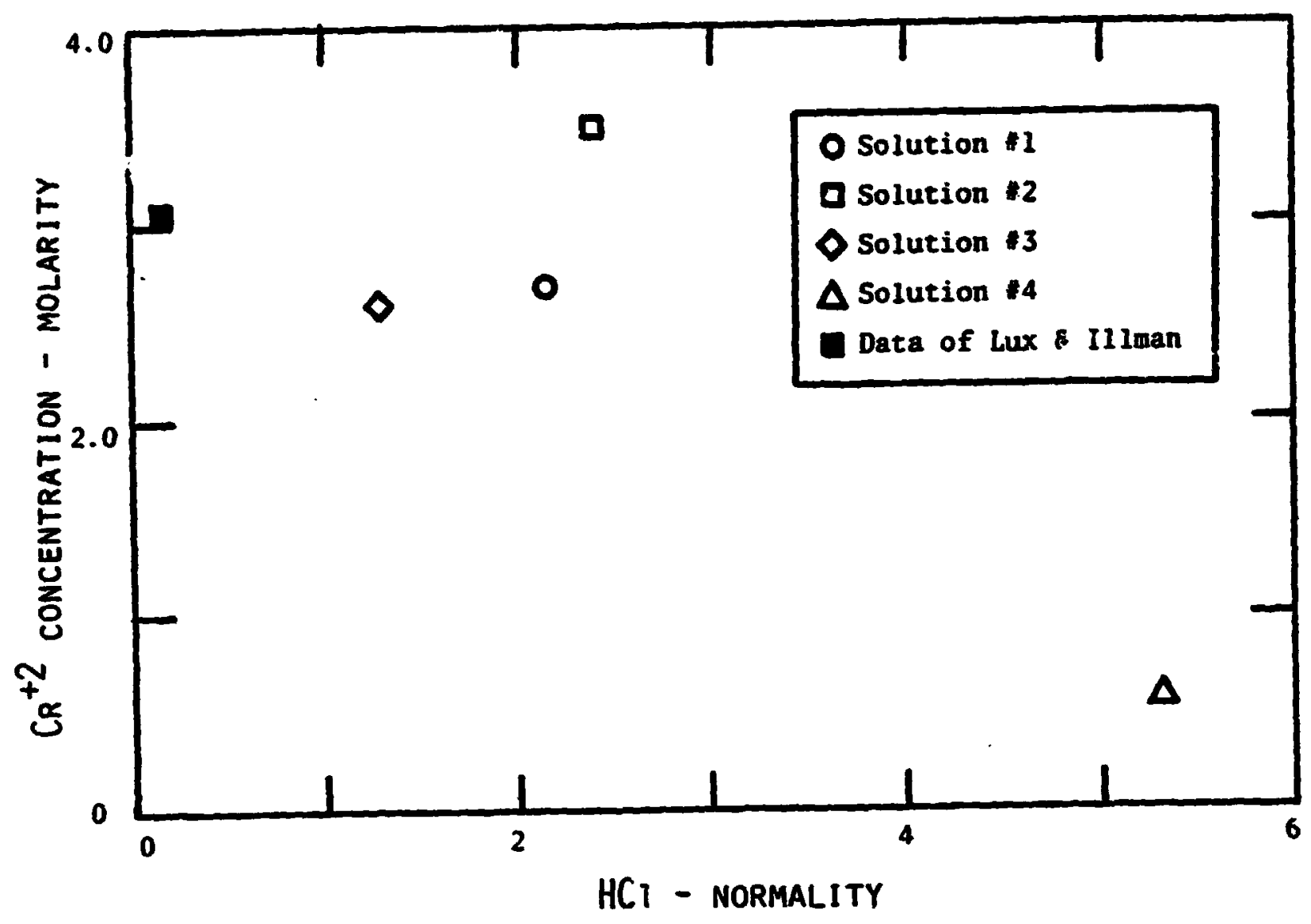

Figure II-1. Chromous Chloride Solubility vs.

Hydrochloric Acid Concentration 


\section{Electrode Material Evaluation}

The fundamental reason for the attractiveness of the $\mathrm{Cr}$ (III)/ $\mathrm{Cr}$ (II)

electrode is its negative potential with respect to the hydrogen electrode. For the sane reason, difficulties were encountered in finding corrosion resistant materials which exhibit good electrocatalytic activity for the chromium (III) chromium (II) electrode reaction and at the same time show a high hydrogen overvoltage.

A screening procedure of candidate electrocatalysts was devised based on the use of slow linear sweep voltammetry in a half-cell configuration. The screening consisted of sequentially measuring (a) hydrogen evolution characteristics of the material in diluted hydrochloric acid, (b) its $\mathrm{Cr}$ (III) reduction characteristics in acidified $\mathrm{CrCl}_{3}$ solution, and (c) its anodic corrosion in diluted hydrochioric acid. Electrode materials which showed satisfactory corrosion and $\mathrm{Cr}$ (III) reduction characteristics were then tested for $\mathrm{Cr}$ (II) electrooxidation in an acidified chromous chloride solution.

in all, the relative performance of 26 electrode materials was evaluated. No single material tested was entirely acceptable with regard to all three requirenents of corrosion resistance, activity and high hydrogen overvoltage. Gold, for instance, exhibited considerable range of stability and favorable electrocatalytic characeristics for the $\mathrm{Cr}($ III $) / \mathrm{Cr}$ (II) reaction, but low hydrogen overvoltage. Lead also exhibited favorable electrocatalytic properties for the chromium reduction and had high hydrogen overvoltage, but it was limited on discharge by corrosion. The identification of gold as a good anodic electrocatalyst and lead as a good cathodic electrocatalyst led to the development of the gold/lead combination electrocatalyst. As shown in Figure 11-2, a combination of gold and lead deposited on carbon was found to offer the advantages of each metal without its disadvantages.

In addition to the above, five dissolved organic compounds (thiourea, palmitic acid, cetyl alcohol, hexanol, and n-propanol) were tested as possible hydrogen evolution inhibitors. 


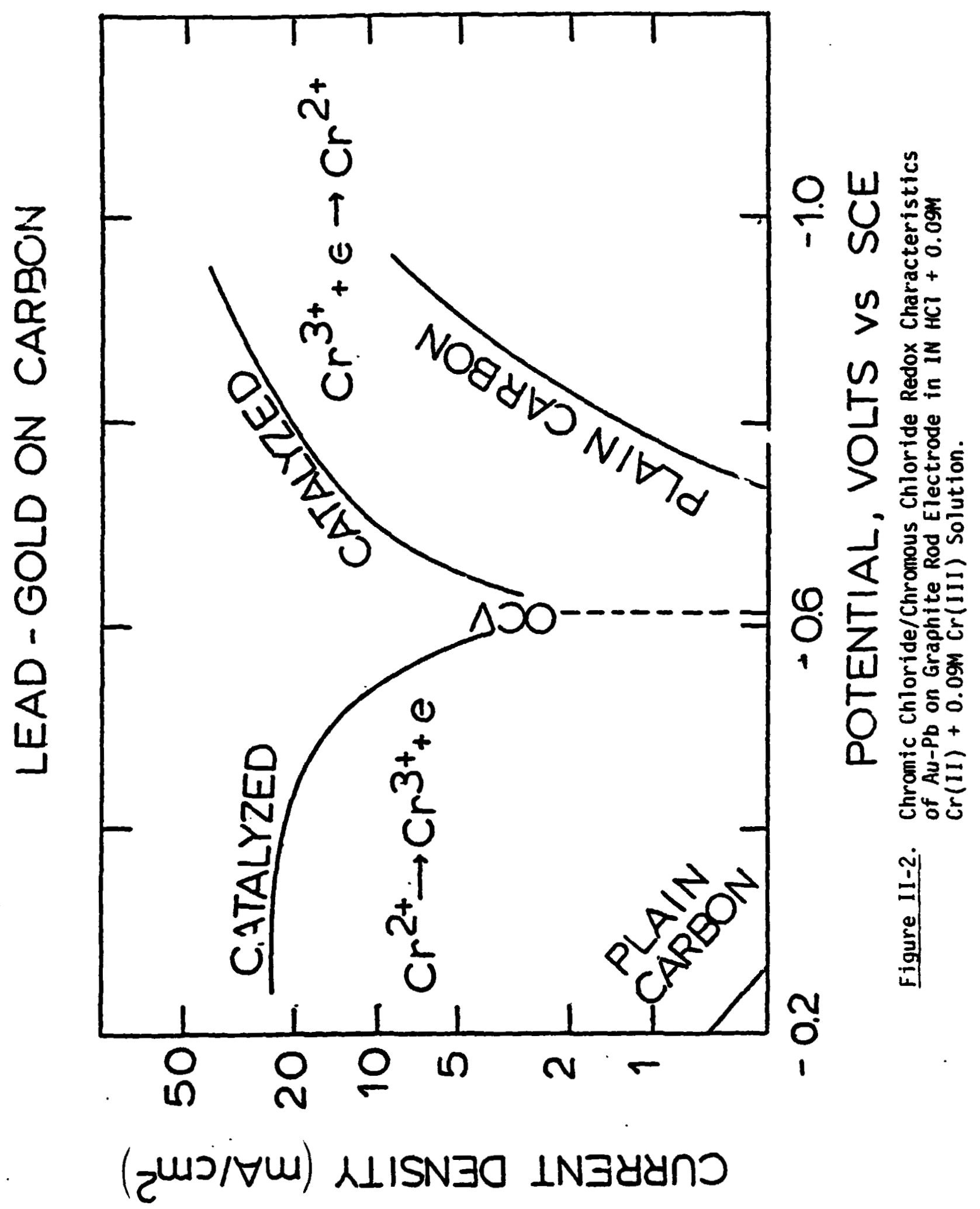




\section{THE EFFECT OF ELECTROLYTE IMPURITIES ON THE CHROMIC CHLORIDE/CHROMOUS CHLORIDE REDOX REACTION}

Low-cost chromium electrolytes are of great interest for application to the $\mathrm{Fe} / \mathrm{Cr}$ redox battery. Since it is inevitable that such low-cost electrolytes will contain some contaminants, it was considered useful as a first screening step to inspect voltarmograms of intentionally contaminated chromium electrolytes. the effects of $\mathrm{Fe}$ (II) and $\mathrm{AI}$ (III) were investigated because these are likely contaminants. Also, an economically attractive, commercially available (McGeon) chromium electrolyte was studied. For this purpose a solution of $1 M$ chromic chloride in $1 M \mathrm{HCl}$ was prepared from a $62 \% \mathrm{CrCl}_{3}$ (McGeon) stock solution.

A. The Effect of Ferrous Ion on the Reduction of Chromic Ion at a Gold/Lead Codeposited Electrode

A gold/lead codeposited on graphite rod electrode of $0.31 \mathrm{~cm}^{2}$ geometric area was prepared as follows. A graphite rod (Ul tra-Carbon \#450-7-6) was wrapped with teflon tape so as to leave exposed onl! whe bottom surface, sanded with 600 grit silicon carbide paper, rinsed thoroughly with distilled water and allowed to dry. Coplating was conducted in a solution of $1.5 \times 10^{-4} \mathrm{M} \mathrm{Pb}^{2+}$, $1 \times 10^{-4} \mathrm{M} \mathrm{Au}^{3+}$ and $1 \mathrm{M} \mathrm{HClO}_{4}$ at $-430 \mathrm{mV}$ (SCE) for ten minutes after which the electrode was removed, rinsed and allowed to dry.

The coplated electrode served as working electrode in a conventional three electrode voltametry cell containing dearated $\mathrm{IM} \mathrm{CrCl}_{3} \cdot 6 \mathrm{H}_{2} \mathrm{O}$ in $\mathrm{IM} \mathrm{HCl}$. A potentiodynamic sweep in stirred solution was performed at $50 \mathrm{mV} / \mathrm{min}$ from $-600 \mathrm{mV}$ (SCE) to $-1100 \mathrm{mV}$. The potential of the working electrode was never allowed to become more positive than $-600 \mathrm{mV}$ in order to avoid lead dissolution. Enough solid $\mathrm{FeCl}_{2}$ to bring the final $\mathrm{Fe}(\mathrm{II})$ concentration to $0.5 \mathrm{M}$ was added while the working electrode potential was slowly scanning from about $-700 \mathrm{mV}$ towards $-600 \mathrm{mV}$. A complete scan from $-600 \mathrm{mV}$ to $-1100 \mathrm{mV}$ was recorded when all the $\mathrm{FeCl}_{2}$ had dissolved.

The results of the experiment described above are preserted in Figure III-1. Adding $\mathrm{Fe}$ (III) enhanced the observed limiting current from $90 \mathrm{~mA} / \mathrm{cm}^{2}$ to $120 \mathrm{~mA} / \mathrm{cm}^{2}$. The onset of the current rise subsequent to the region of 1 imiting current seems 
ORI JNNAL PAGE IS

OF POOR QUAIT

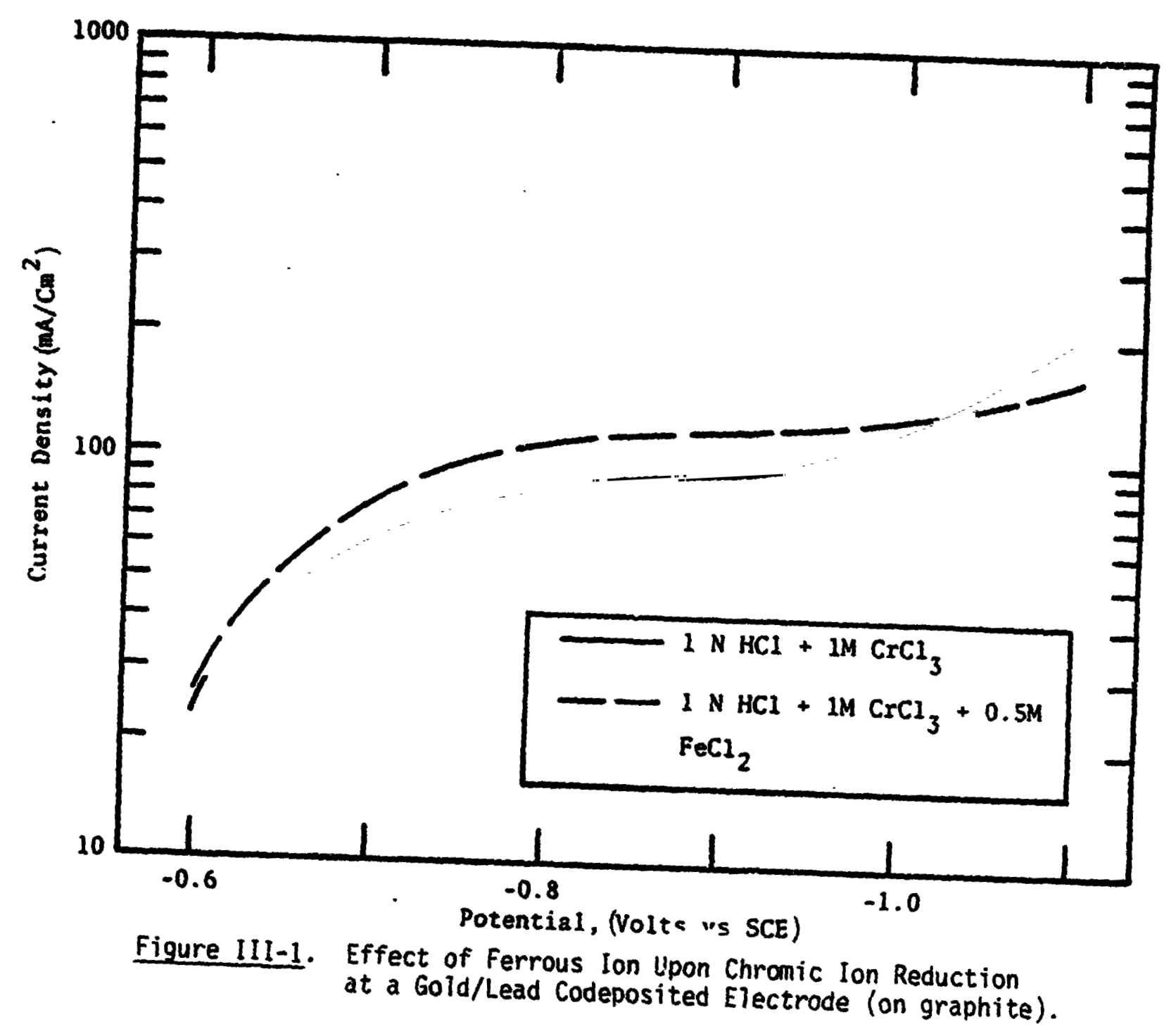




\section{ORICINAL PACE is \\ OF POOR QUALTY}

to occur at a more negative potential when $\mathrm{Fe}(\mathrm{II})$ is added. It is encouraging that a rapid rise in current (as might be expected for hydrogen evolution on $\mathrm{Fe}$ ) is not observed. It is conciuded that further experiments are necessary to clarify the effect of $\mathrm{Fe}(\mathrm{II})$. These would include measurement of the $\mathrm{Fe}^{2+}+2 \mathrm{e} \rightarrow \mathrm{Fe}$ reaction in $\mathrm{HCl}$ and measurement of the hydrogen evolution reaction at the gold/lead codeposited electrode.

B. The Effect of Aluminum (III) Ion on the Reduction of Chromic Ion at a Gold/Lead Codeposited Electrode

Figure III-2 illustrates the effect of $10^{-2} \mathrm{M} \mathrm{AI}{ }^{3+}$ on $\mathrm{Cr}(I I I)$ reduction

at a gold/lead codeposited electrode. After testing in snlution containina AI(III), the electrode was removed from solution, rinsed with distilled water and placed in an $\mathrm{Al}(\mathrm{III})$ free solution. This procedure may have resulted in some loss of lead. The effect of $A 1$ (III), if any, appears to be small. Electrodeposition of Al under the conditions of this experiment would, of course, not be expected.

C. Comparison of Fisher and McGeon Chromic 'loride Solutions

The electrochemical behavior at a gold/lead codeposited electrode in a $1 M \mathrm{Cr}^{3+}, 1 \mathrm{M} \mathrm{HCl}$ (Fisher) solution is compared to a $1 \mathrm{M} \mathrm{Cr}^{3+}, 1 \mathrm{MCl}$ (MCGeon) solution in Figure III-3. There is no discernable difference in behavior in these tests. We therefore recommend that the economically advantageous McGeon solution be investigated further; for example: (1) voltammetry of an $80 \%$ chromous chloride solution to simulate the final portion of charging where problems reportedly occur, (2) voltametry at more anodic potentials than the region of chromic reduction to find evidence of other Faradaic processes, and (3) electropurification of the McGeon solution, if necessary.

NASA-LERC ${ }^{(9)}$ continued further investigations with the chromium solution from McGeon. They found that upon repeated cycling with the McGeon solution, electrode poisoning occurred and the cell polarization increased as shown in Figure III-4. Chemical analysis showed high organic impurities -- particularly carbonyls which could have resulted from an organic reduction step used in the preparation of the chromic chloride solution. Separation of organics improved the performance somewhat, but not enough to justify further work. 


\section{jaICINAL PAGE IS}

OF POOR QUALITY

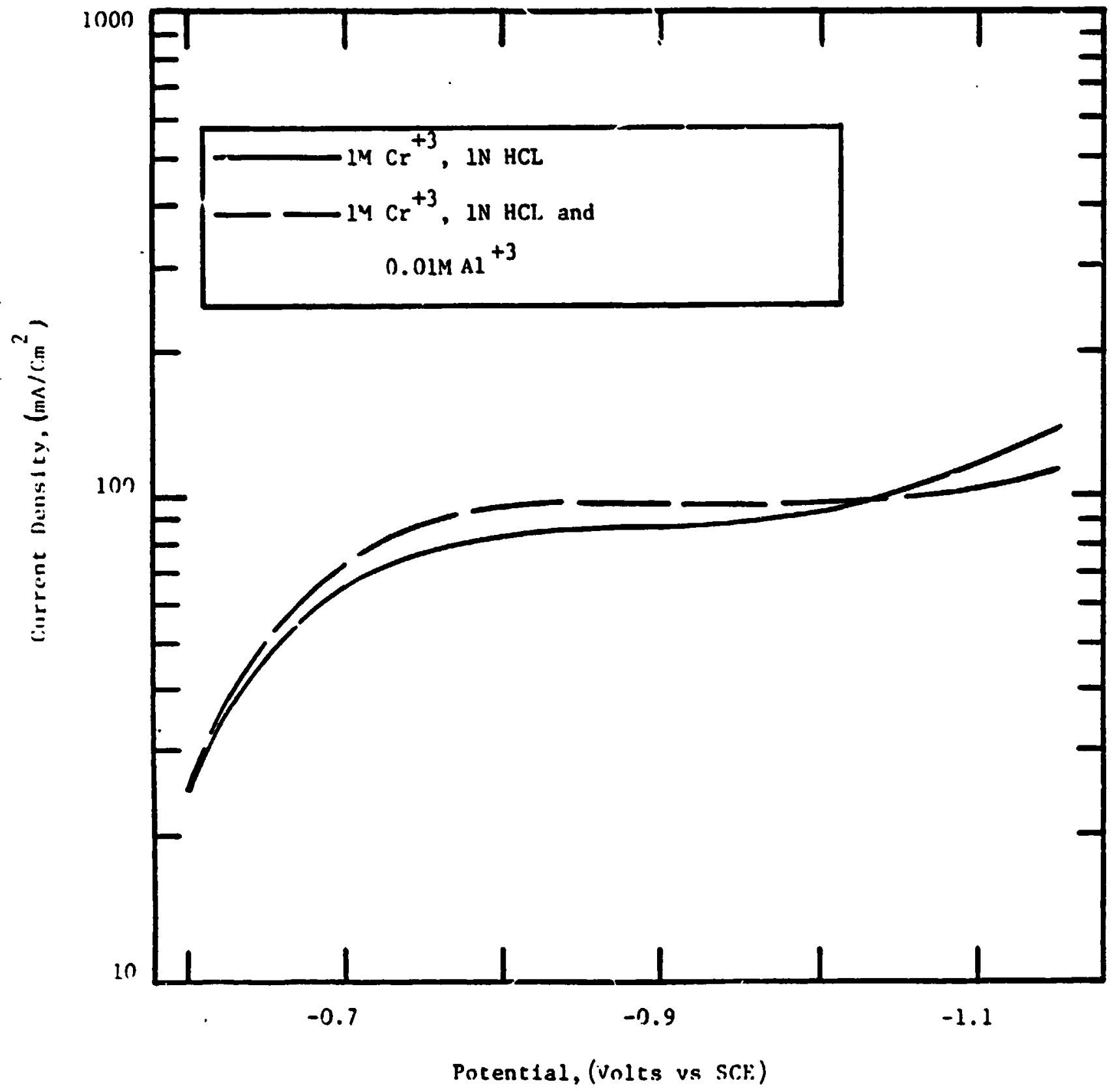

Figure III-2. Effect of Aluminum (III) Ion Upon Chromic Ion Reduction at a Gold/Lead Codeposited Electrode (on graphite). 
ORIGINAL PACE IS
OF POOR QUALIT

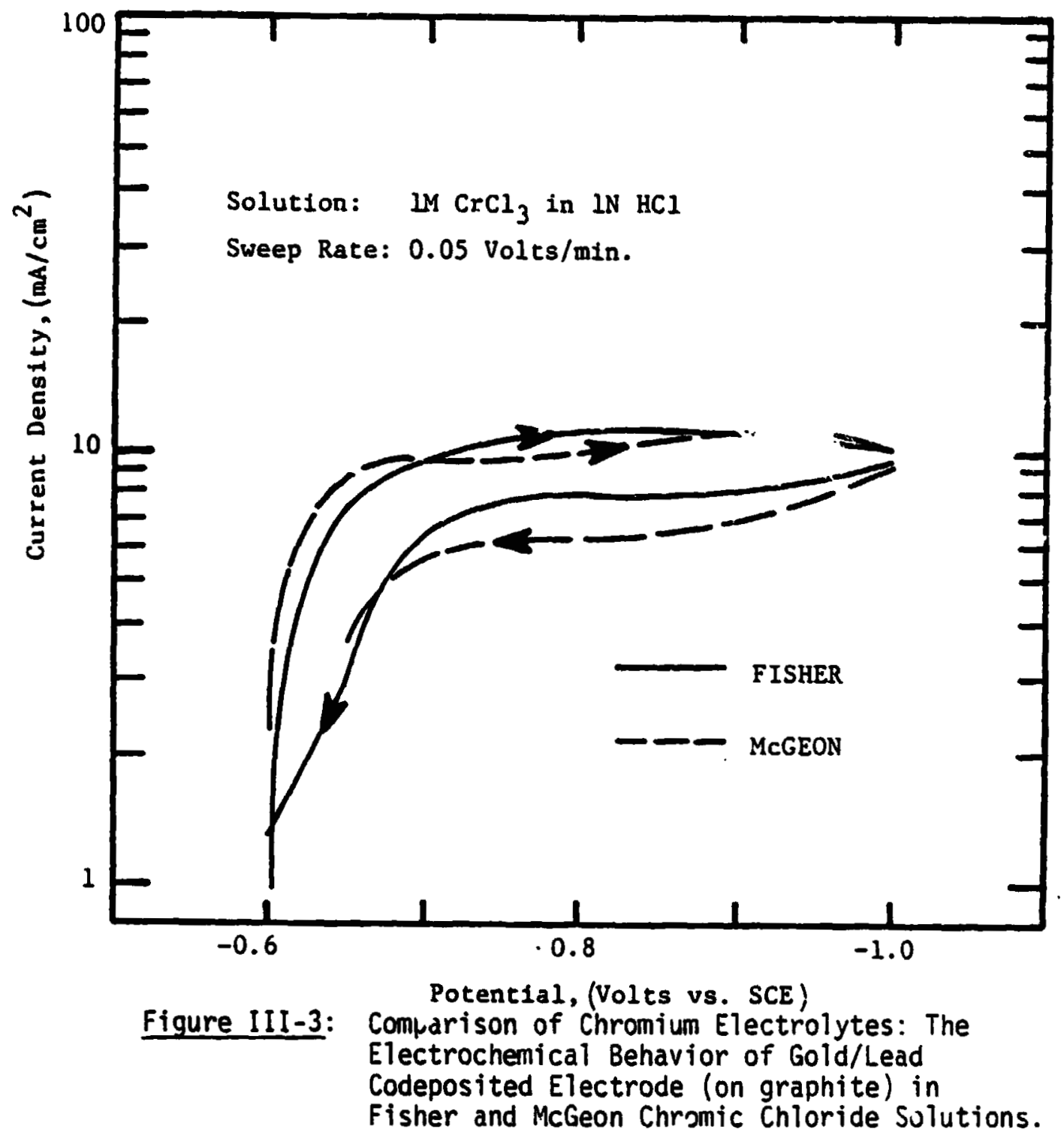




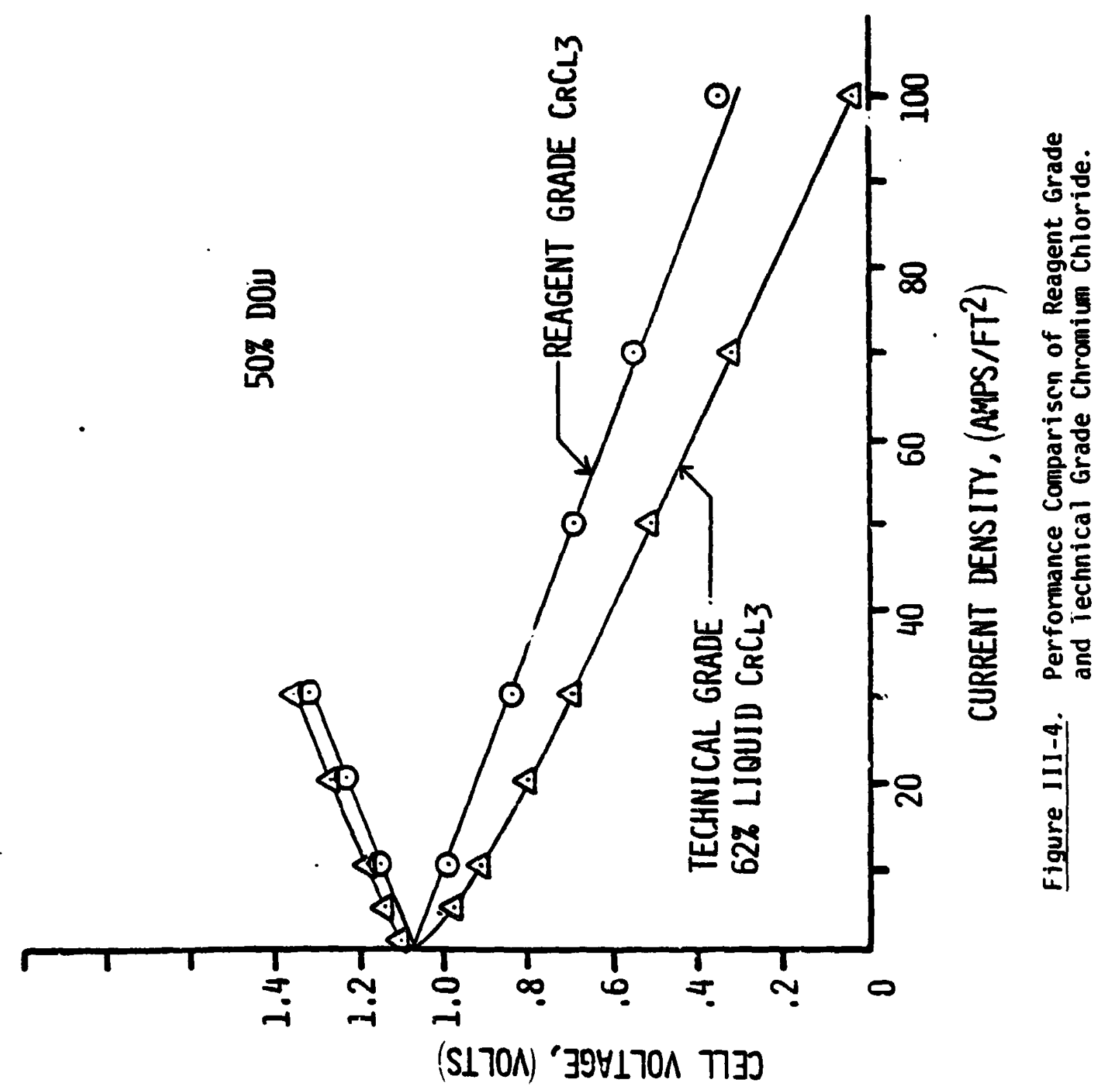




\section{INVESTIGATION OF THE COMPLETE IRON/CHROMIUM REDOX SUBSCALE CELL}

The overall objective of the complete subscals cell work originally pmposed was optimization of the concentration and method of application of electrocatalysts for the $\mathrm{Cr}(I I I) / \mathrm{Cr}$ (II) electrode. The immediate objective of the work reported here was to gain experience in operating a cino lete subscale cell using baseline catalyzation procedures. The optimization task was superceded by a request from NASA-LERC to perform the task described in Section III of the report.

\section{A. Subscale Description}

A schematic of the subscale redox fiow cell used is provided in figure IV-1. The positive electrolyte was $50 \mathrm{ml}$ of $\mathrm{IM} \mathrm{FeCl}_{2}$ in $2 \mathrm{M} \mathrm{HCl}$. The negative electrolyte was $50 \mathrm{ml}$ of $1 \mathrm{M} \mathrm{CrCl}_{3}$ in $24 \mathrm{HCl}$. For electrocatalysis, the chromium solution was made $: 0^{-3} \mathrm{H}$ in $\mathrm{PbCl}_{2}$ by adding five drops $(n .17 \mathrm{ml})$ of $2 \mathrm{M} \mathrm{HCl}$ solution

that was saturated with $\mathrm{PbCl}_{2}$. Active electrode area was $14.5 \mathrm{~cm}^{2} . \mathrm{A}_{2} \mathrm{SO}_{4}$ cleaned carbon felt served as an inert electrode on the positive side of the cell, while a thermally deposited gold on carbon felt (Appendix A) served as a inert electro 'e on the negative side of the cell. An Ionics, Inc. ion exchange menbrane, CDIL-AS(25NP), was used as a separator. Each flow-through carbon felt electrode was gasketed with a piece of $0.05^{\text {" }}$ thick polyethylene cut to the appropriate shape. Two wax-impregnated graphite end-plates completed the "sandwich cell." The sandwich was held together by running a series of insulated bolts completely through the sandwich at its edges and tightening with nuts. Each graphite end-plate had an inlet and an outlet port for the circulation of electrolyte. Two oscillating bench pumps (later changed to dual Bellows metering pumps) were used for circulation. Inert plastic materials were used for the ports and associated tubing. The electrical contacts to the graphite end-plates were made by attaching standard electrical ?ugs to the plates. 


\section{ORIGINAL PAGE IS}

OF POOR QUALTT

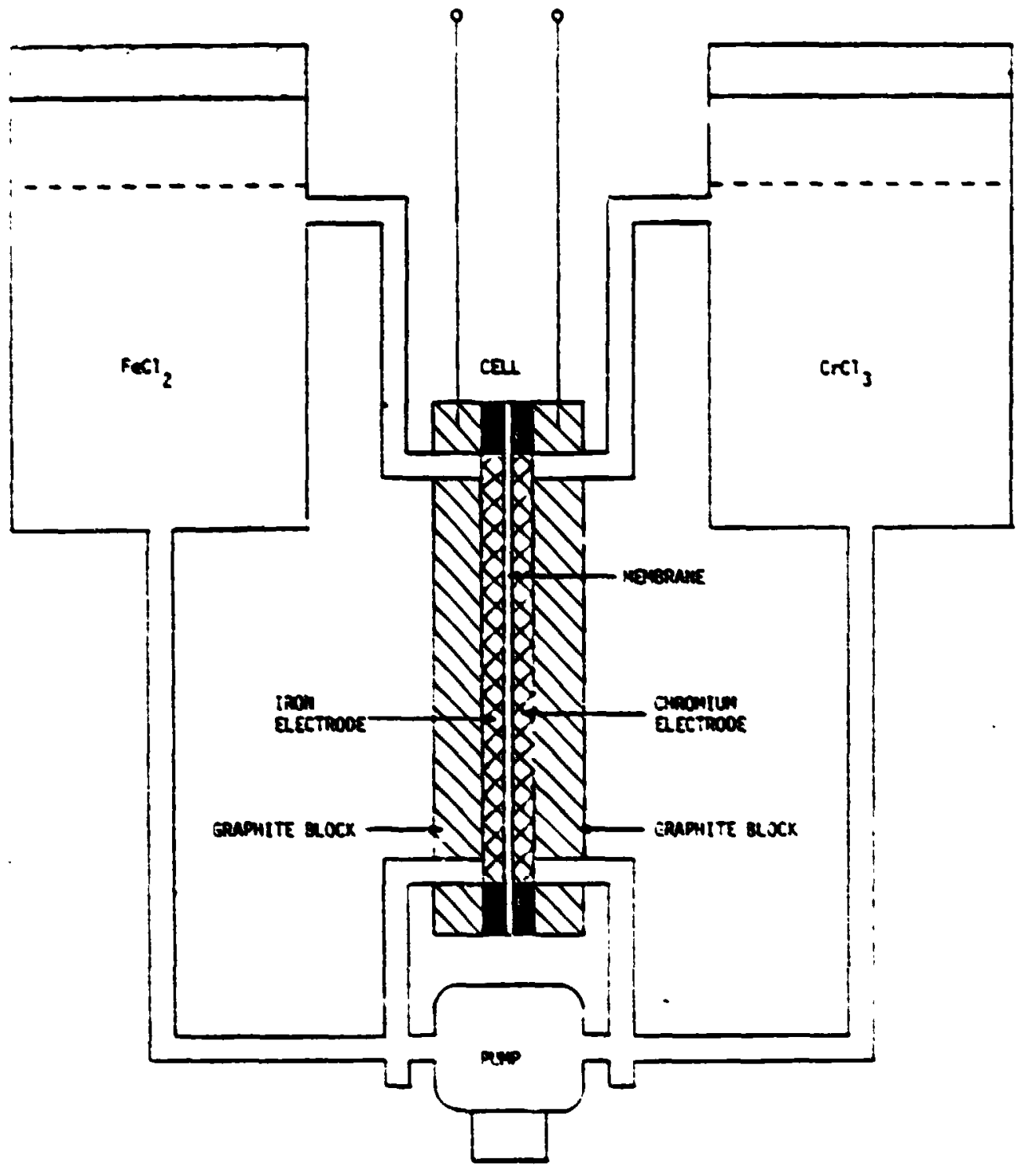

Finere iV-1. Subscale fion Cell sysed 


\section{B. Polarization Measurements in Complete Cell}

The subscale redox battery was operated using the procedures similar to those used at NASA-LeRC ${ }^{(10)}$ except that a saturated calomel electrode (SCE) was placec into the chronium inlet of the flow cell. The cell was charged and discharged using a constant current supply. During charge, the cell voltage was limited to 3.25 volt; during discharge care was taken (when necessary, the discharged current was reduced) to avoid cell reversal. For each cilarge/discharge cycle, the current and cell voltage were monitored. The total charge onssed and the (ideal) state of charge (assuming no side reactions) was determined from the ampere-hour measurements.

A series of charge/discharge cycles was performe-j; the results are given in Table IV-1. On the last test more complete polarization measurements were made. The cell was charged to $29 \%$ state of charge at $312 \mathrm{~mA}$ and discharged to 5: using stepwise discharge currents of $314 \mathrm{~mA}, 200 \mathrm{~mA}$ and $100 \mathrm{~mA}$. The results are presented in Table IV-2. The amount of polarization is small and could be mostly due to membrane resistance. The measured value of the potential of the chromiun electrode versus the SCE agreed very well with the expected value for a reversible $\mathrm{Cr}(I I I) / \mathrm{Cr}$ (II) electrode.

The workability of our subscale full cell test equipment had been established. Any further testing in the complete cell mode, however, was terminated to pursue the investigations of the electrodes fabricated by the $8 / 79$ batch of Fiber Materials Inc. (FMI) carbon felts received by IASA. The electrodes fabricated with this particular batch of carbon felt showed reduced chromium activity and high hydrogen evolution (see Section III). 
TABLE IV-I

FULL CELL TESTING

Charge/Discharge state of Charge $\begin{array}{cc}\text { Cell } & \text { App:ieo } \\ \text { Polarization } & \text { Current }\end{array}$

\section{FIRST TEST}

$\left(\begin{array}{l}\text { System charged } \\ \text { up to } 92 \%\end{array}\right)$

SECOND TEST

$\left(\begin{array}{l}\text { System charged } \\ \text { up to } 94 \%\end{array}\right)$

Charge

Discharge

$36 \%$

94\%

87:

Discharge
THIRD TEST

First Cycle

$\left(\begin{array}{l}\text { System charged } \\ \text { to 67: }\end{array}\right)$

Second uycle

$\left(\begin{array}{l}\text { System charged } \\ \text { to 77\% }\end{array}\right)$

Third Cycle

$\left(\begin{array}{l}\text { Systen charge } \\ \text { to 81: }\end{array}\right)$
Charge

Discharge

Charge

Discharge

Charge

Discharge

Discharge
$67 \%$

67\%

$56 \%$

$28 \%$

$75 \%$

$68 \%$

16.
$162 m V$

$688 \pi V$
$142 \pi \mathrm{V}$

High

$289 m A$

$14 m A$
$50 \mathrm{~mA}$

$14 \mathrm{~mA}$

$90 \mathrm{nV}$

$217 m A$

$40 \mathrm{mV}$

$100 \mathrm{~mA}$

$105 \mathrm{mV}$

$200 \mathrm{~mA}$

$82 m V$

$150 \mathrm{nA}$

$53 m v$

$280 \mathrm{~mA}$

$186 \mathrm{mV}$

$312 \mathrm{~mA}$

$110 \mathrm{mV}$

$75 \mathrm{~mA}$ 
TABLE IV-2

\begin{tabular}{|c|c|c|c|c|}
\hline Cycle & $\begin{array}{r}\text { State of } \\
\text { Charge (x) }\end{array}$ & $\begin{array}{c}\text { Polarization } \\
\text { (mV) }\end{array}$ & $\begin{array}{l}\text { Current } \\
\text { (mA) }\end{array}$ & $\begin{array}{l}\text { Equivalent } \\
\text { Polarization } \\
\text { at } 312 \mathrm{ma} \\
\text { (mV) }\end{array}$ \\
\hline Charge & 4 & 193 & 312 & 193 \\
\hline Charge & 23 & 150 & 312 & 150 \\
\hline Charge & 29 & 146 & $31 ?$ & 145 \\
\hline Discharge & 29 & 179 & $3 i ?$ & 179 \\
\hline Discharge & 20 & 208 & 314 & 208 \\
\hline Discharge & 20 & 139 & 200 & 218 \\
\hline Discharge & 10 & 173 & 200 & 270 \\
\hline Discharg: & 10 & 100 & 100 & 312 \\
\hline Discharge & 7 & 121 & 100 & 378 \\
\hline
\end{tabular}




\section{INVESTIGATION OF ELECTRODE PREPARATION PROCEDURES}

The gold-lead electrocatalyst combination was applied by NASA-LeRC to porous electrodes made of carbon felts. Anong several carbon substrates eyaluated at MASA-LeRC for electrode substrates, a graphite/carbon felt structure yielded the necessary sheet flow characteristics with a small pressure drop. Uniform gold deposition was achieved by a simple impregnation technique using aqueous gold chloride solution followed by thermal decomposition at $250^{\circ} \mathrm{C}$. Lead was deposited, subsequently, by in situ electroplating via addition of lead chloride solution to chromium chloride electrolyte. Both graphite and carbon felts showed good and equal performance; and the carbon felt was selected due to its lesser cost. This process is detailed in Appendix A and was used as a "standard" or baseline process. Initially, this process gave a very good success rate; electrodes prepared by this technique showed high activity for the chromium reacx reaction and hign polarization for hydrogen evolution.

In scaling up the system, MASA-LERC purchased a new lot of carbon felt from the same vendor (Fiber ifaterials, Inc.). NASA found that electrodes prepared with this new lot had much higher rates as well as poorer voltages on discharge ${ }^{(10)}$ of hydrogen evolution than those made with the original lot. This felt is identified as "poor" or $8 / 79$ felt. The manufacturer could not suggest any obvious reasons for the differences. An extensive program was carried out at Giner, Inc. to characterize the felts and to find a "normalization" procedure which would produce satisfactory electrodes from any lot of felt. The procedures and the results of this program are described below.

\section{A. Physical Characterization:}

The physical properties measured were average weight per unit area (three determinations), hydrophobicity and the pH of felt soaking water, using samples of $14.5 \mathrm{~cm}^{2}$ projected area from three lots of carbon felt (NASA old, 3,79 and 10/79) and three lots of graphite felt (12/79A, 12/79B and 12/79C). 
Fifty $\mathrm{ml}$ of distilled water was placed in a beaker and its $\mathrm{pH}$ measured with a combination pH electrode standardized against commercial pH buffers. A weighed dry felt sample was immersed in the beaker containing the $50 \mathrm{ml}$ distilled water at room temperature and stirred for one minute. The felt was then arasped at one corner with tongs, lifted out of the water and drained against the side of che beaker for thirty seconds. The wet felt was weighed. The difference in weight between the, wet and dry felts is temed the initial water retention - The water capacity was determined as follows. The weighed wet felt mentioned above was returned to the same water containing beaker. The beaker was placed in a vacuum dessicator and a vacuum was pulled for thirty minutes with a water aspirator. The felt was removed, drained against the side of the beaker for thirty seconds and weighed. The $\mathrm{pH}$ of the felt soaking water remaining in the beaker after vacuun impregnation was measured.

Table $V-1$ gives the results of physical property measurements for the six types of felt investigated. The average weight per unit area was significantiy greater for the carbon 8/79 (NASA new) felt than for the NASA old felt. Another lot of felt obtained at a later date, 10/79 felt, showed an intermediate value. In the case of graphite felts, 12/79/A and 12/79/B have average weight per unit areas, similar to iNASA old ielt. Graphite felt $12 / 79 / \mathrm{C}$ has a high average weight per unit area similar to $8 / 79$ felt. The NASA old felt is clearly the most "wettable" carbon felt. The least "wettable" felt of all is $8 / 79$ which is the batch that gave the poorer success rate using the standard activation technique of IASA-LERC. Interestingly, the $8 / 79$ batch also has the lamest soak water $\mathrm{pH}$ change, indiciting its surface chemistry is different from the other felts or contains alkaline impurities. The lot-to-iot variability in physical properties of graphite felt is less than that of carbon felt. One graphite felt, 12/79/8, has virtually identical properties to the NASA old felt which had given a high success rate using standard activation procedures. A comparison of the volt- 


\begin{tabular}{|c|c|c|}
\hline Felt Sample & $\begin{array}{l}\text { Height } \\
\left(\mathrm{mg} / \mathrm{cm}^{2}\right) \\
\end{array}$ & $\begin{array}{l}\text { Water Retention } \\
\left.\text { (mg } \mathrm{H}_{0} 0 / \mathrm{mg} \text { felt }\right)\end{array}$ \\
\hline
\end{tabular}

\begin{tabular}{|c|c|c|c|}
\hline 01d carbon felt & 19.6 & 11.7 & 11.4 \\
\hline 8;79 carbon felt & 27.4 & 1.68 & 8.66 \\
\hline 10/79 carbon felt & 23.8 & 5.25 & 7.37 \\
\hline
\end{tabular}

12/79-A graphite

felt 22.0

22.0

8.57

8.09

5.4

12/79-B graphite

felt

21.4

11.2

11.8

6.1

12/79-C graphite felt

28.1

6.07

8.36

5.1 
ammetric behavior of these two felts was carried out and described below.

B. Activation by "Standard" Procedure:

Samples of $14.5 \mathrm{~cm}^{2}$ were cut from each of the four felts designated as (A) NASA old carbon felt, (B) $8 / 79$ carbon felt, (C) 10/79 carbon felt, and (D) $12 / 79$ graphite felt. These samples were put through the standard impregnation/thermal decomposition procedure.

We rade some very interesting observations about the gold impregnation step. As explained in Appendix A, the thermal gold deposition process involves soaking the felt in a $1.25 \times 10^{-3} \mathrm{M} \mathrm{Au}{ }^{3+}$ solution. A dramatic difference was observed in the gold soaking solutions after the felts had soaked overnight. The MASA old, 10/79, and graphite felts behaved sinilarly in that there was little color change of the gold chloride solution (the soaking solution maintained its characteristic pale yellow color) whereas the $8 / 79 \mathrm{felt}$ soaking solution becane colorless. When the felt samples were placed on blotting paper, the NASA old, 10/79, and graphite felts discolored the paper with the gold solution which drained from the felts. The $8 / 79$ felt, however, did not produce any coloration on the adsurbent paper. It was evident that the $8 / 79$ felt had picked up all gold which amounted to about $60 \mu \mathrm{g} \mathrm{Au} / \mathrm{cm}^{2}$. This was contimed by chemical analysis by neutron activation at NASA-LekC. By comparison, the good felt had picked up only $20 \mu \mathrm{g} \mathrm{Au/}$ $\mathrm{cm}^{2}$. These results, taken with the $\mathrm{pH}$ test described above, provide a strung evidence that different lots of the carbon felt vary widely in their surface chemistry.

C. Electrochemical Screening of Felts Activated by Standard Procedures

1. Constant Potential Technique:

A constant potential technique was used to coripare different felts and to evaluate the effect of various ster in the NASA-LeRC standard method for making chromium redox electrodes. Four samples of $14.5 \mathrm{~cm}^{2}$ were cut from each of the three carbon felt lots designated as (A) old felt, (B) $8 / 79$ felt, and (C) $10 / 79$ felt. 
"NASA old" was a lot that had been yielding "good" electrodes, while the 8/79 felt had not. These samples were put through the standard NASA-LeRC activation procedure. After each step, one $14.5 \mathrm{~cm}^{2}$ sample was taken from each of the felt lots. Three $8 \mathrm{~mm}$ diameter $\left(0.5 \mathrm{~cm}^{2}\right.$ projected area) disks were punched out of each $14.5 \mathrm{~cm}^{2}$ sample. Each disk was placed in a tantalum wire coil current collector and tested in a half-cell. A universal electrochemical cell assently (e.g. ECO Model 494) as shown in Figure $V-1$ was used for all these experiments. The cell container is a $75 \mathrm{ml}$ glass jar threaded to accept a Moplen screw head with 5 holes designed to accept ground glass taper joints. The counter electrode is a spectrographically pure graphite rod (U1tra-Carbon " $F$ ") and the reference electrode is a saturated calomel electrode (SCE). A gas bubbler is equipped with two way stopcock so that nitrogen can be either bubbled through electrolyte or swept over the surface of the electrolyte. In all cases, $50 \mathrm{ml}$ of solution was used; all tests were performed at room temperature.

All solutions were deaerated with prepurified nitrogen. Fresh solution was used for each three disk series. The working electrode was placed in the cell while potentiostated at $-0.5 \mathrm{~V}$ (SCE) except that lead plated electrodes were potentiostated at $-0.7 \mathrm{~V}$ to prevent deplating. After one minute the potential was stepped with a preset bias box to $-1.0 \mathrm{~V}$ and the currents after 50 seconds and 100 seconds were measured. After two minutes at $-1.0 \mathrm{~V}$, the potential was stepped back to its original value for one minute and the whole process repeated. For each sample tested, the first 50 second measurement was identical to the second 50 second measurement. The two 100 second measurements likewise were reproducible.

Table V-2 presents the results of voltammetric experiments designed to compare different felts and evaluate the several steps in the standard method for making chromium redox electrodes. As expected, in all cases hydrogen evolution currents were relatively small on bare carbon felts and significantly increased after gold deposition. After the thermal gold deposition step, 10/79 felts on the average 


\section{ORIGINAL PAGE IS \\ OF POOR QUALITY}
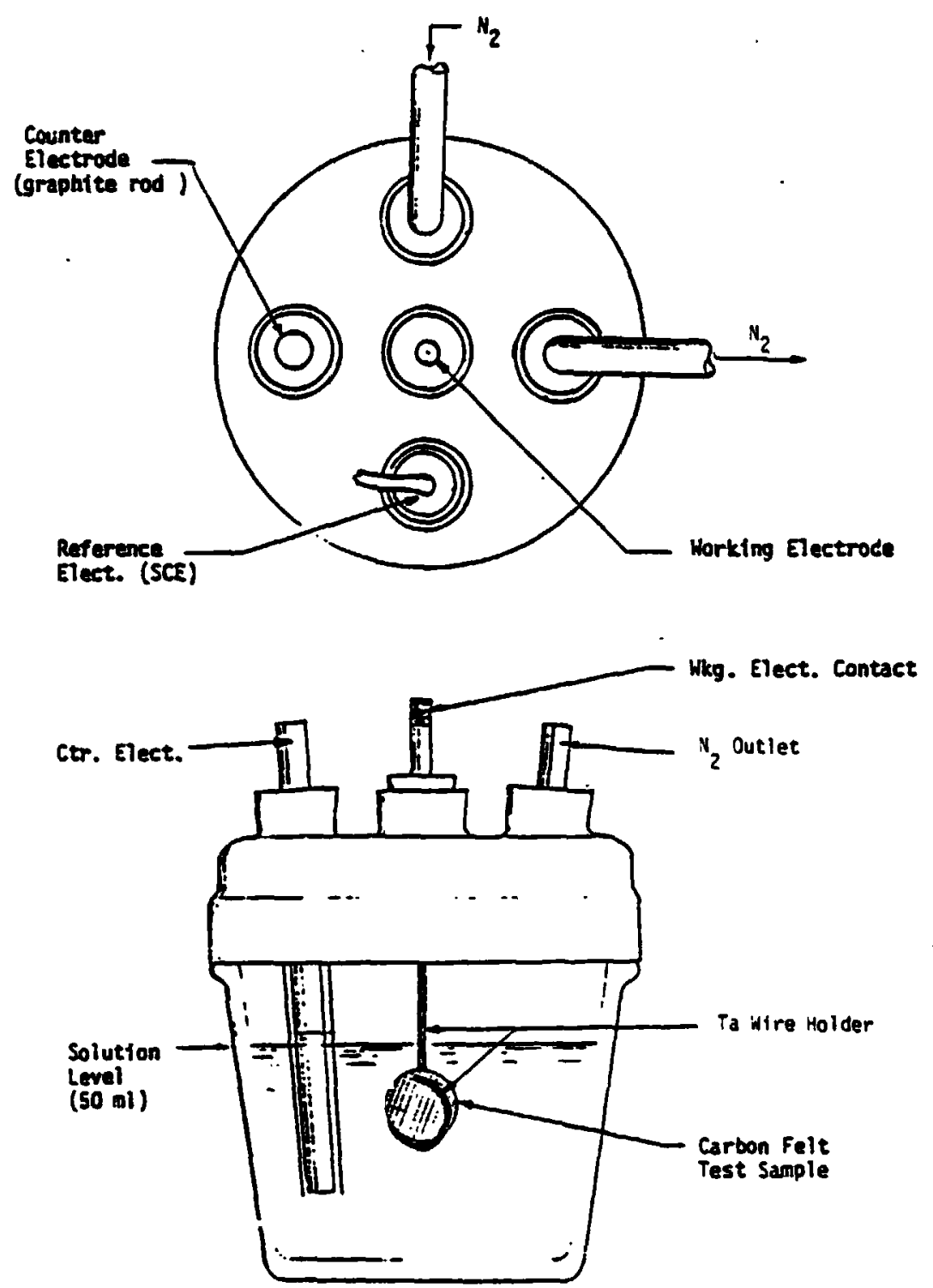

Elqure V-1. Cell Configuration with Ta - Wire Holder 
TABLE V-2

$\mathrm{H}_{2}$ EVOLUTION CURRENT ${ }^{*}$ IN MA AT -1.00 VOLT IN IN HCI OF

THREE CARBON FELTS AFTER DIFFERENT STAGES IN THE ACTIVATION PROCEDURE

Felt As Received

$50 \mathrm{sec}$

$100 \mathrm{sec}$

After Cleaning in

Sulfuric Acid

$\begin{array}{r}50 \mathrm{sec} \\ 100 \mathrm{sec} \\ \text { After Thermal Gold } \\ \hline\end{array}$

$50 \mathrm{sec}$

$100 \mathrm{sec}$

After Electroplated Lead

$50 \mathrm{sec}$
$100 \mathrm{sec}$
ter Electroplated Lead

NASA 01d

3.41

3.5

0.77

0.677

5.93

5.38

2.20

2.12

3.01

2.94

8/79 Felt:

2.94

10/79 Felt

2.07

1.59
$50 \mathrm{sec}$
4.53
6.81
$100 \mathrm{sec}$
4.65
6.84
* The currents are averages of 3 samples from each felt and duplicate': sts for each sample.

18.5

18.7 
gave more hydrogen evolution than NASA old felt; $8 / 79$ felt clearly gave the largest hydrogen evolution current. The magnitude of hydrogen evolution for each felt decreased after the lead electroplating step, but once again the 10/79 felt showed somewhat greater current than NASA old felt, and the $8 / 79$ felt gave the most current. These results are in complete agreement with the observations by NASA-Lewis on the performance of electrodes in complete cells.

\section{Linear Sweep Vultanmetry:}

A slow scan rate, linear sweep voltammetry in stirred solution was also used to evaluate electrochemical properties of the three carbon felts and one araphite felt. The approach taken was to compare initial current-voltage profiles in four different electrolytes.

These are:
A) $\mathrm{IN} \mathrm{HCl}$
B) $\quad \mathrm{N} \mathrm{HCl}+0.5 \mathrm{M} \mathrm{CrCl}$
C) $1 \mathrm{~N} \mathrm{HCl}+0.5 \mathrm{M} \mathrm{CrCl}_{3}+10^{-4} \mathrm{M} \mathrm{PbCl}_{2}$
D) $1 \mathrm{~N} \mathrm{HCl}+10^{-4} \mathrm{M} \mathrm{PbCl}_{2}$

All experiments described here were carried out in the above described half cell assembly. An electrocis sample was placed in a tantalum wire coil sample hoider and immersed in solution. The electrode was held at $-0.250 \mathrm{~V}$ vs. SCE for about 1 minute and voltarmetry was performed beginning at $-0.250 \mathrm{~V}$ and sweeping more negative to $-1.2 \mathrm{~V}$ at a sweep rate of $0.25 \mathrm{~V} /$ minute. Most scans presented here are after 3-4 sweeps when the curves became reasunabiy reproducible. No attempt was made to correct for IR drop between the reference and working electrodes since the purpose was only to compare different felts and catalyzation techniques.

After making sweeps in $1 \mathrm{~N} \mathrm{HCl}$ (solution A) to measure hydrogen evolution currents, the cell solution was switcined to $0.5 \mathrm{M} \mathrm{CrCl}_{3}$ in $1 \mathrm{~N} \mathrm{HCl}$ (solution $B$ ). After performing sweeps in the chromic chloride solutions, 5 drops $(\sim 0.17 \mathrm{ml})$ of 
aqueous solution of saturated $\mathrm{PbCl}_{2}$ were added to the cell solution to make solution $\mathrm{C}\left(0.5 \mathrm{M} \mathrm{CrCl}_{3}+1 \mathrm{~N} \mathrm{HCl}+10^{-4} \mathrm{MA} \mathrm{PbCl}_{2}\right)$. Sweeps in solutions $\mathrm{B}$ and $\mathrm{C}$ nrovide a measure of chromic reduction reaction without lead ions and with lead iuns, respectively. The electrode was rinsed with distilled water a.d a solution of fresh IN $\mathrm{HCl}$ with $10^{-4} \mathrm{M} \mathrm{PbCi}_{2}$ (Solution 0 ) was substituted and the sweep repeated.

Baseline Electrode: The first series of such sweeps was carried out on NASA old felt. Figure V-2 shows current potential curves for NASA old carbon felt in "as received" condition. The bare felt (without any gold) shows very little hydrogen e:olution in $1 \mathrm{~N} \mathrm{HCl}$. When lead is added, as expected from our previous work $(4,5)$, lead on carbon felt further reduces the hydrogen evolution in $\mathrm{HCl}$ and shows very good $\mathrm{Cr}$ (III) reduction activity.

The polarization curves obtained on the NASA old carbon felt electrode containing $25 \mathrm{\mu g} \mathrm{Au} / \mathrm{cm}^{2}$ ( $\mathrm{gy}$ the standard activation procedure) with and withnut incorporation of lead are presented in Figure $v-3$. These curves show that the incorporation of lead onto the electrode surface suppresses hydrogen evolution and greatly increases the cataiytic activity for $\mathrm{Cr}(I I I)$ reduction reacti. . snears that hydrogil evolution on gold surface not only contributes to the efficiency loss by parasitic power consumption during sharging but also retards $\mathrm{Cr}$ (III) reduction reaction by competing for catalytically active sites.

Comparison of Carbon Felts: A comparison of three batches of carbon felts catalyzed by the standard impregnation/tiermal decomposition technique is shown in figure $V-4$. Clearly, there are large differences in hydrogen evolution currents. The chromium reduction currents remain about the same, assumming that the chromium reduction and hydrogen evolution processes occurring in $1 \mathrm{~N} \mathrm{HCl}+0.5 \mathrm{M} \mathrm{CrCl}_{3}$ (with or without $\mathrm{PbCl}_{2}$ ) are independent and additive.

Once again, the 10/79 folt demoristrated electrochemical properties intermediate to those of the NASA ald felt and the $8 / 79$ felt. This pattern indicates some kind of 


\section{comcenal page ls \\ Of POOR QUALT'}

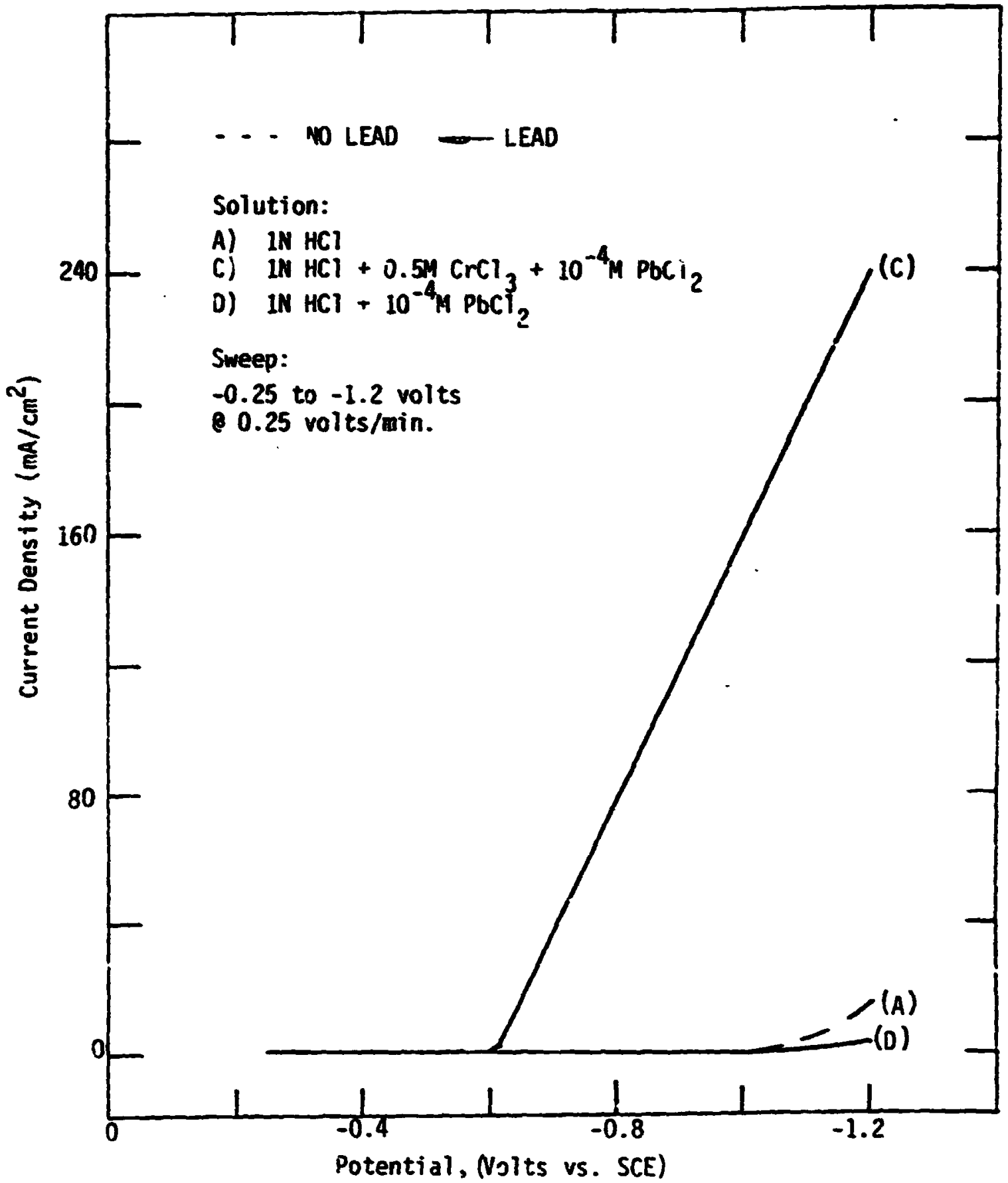

Figure V-2. Hydrogen Evolution and Chromic Ion Reduction on a Bare Carbon Felt, with and Without Lead Chloride (NASA "Old" Felt with No. Gold). 


\section{ORenul pase is}

of POoR qualm

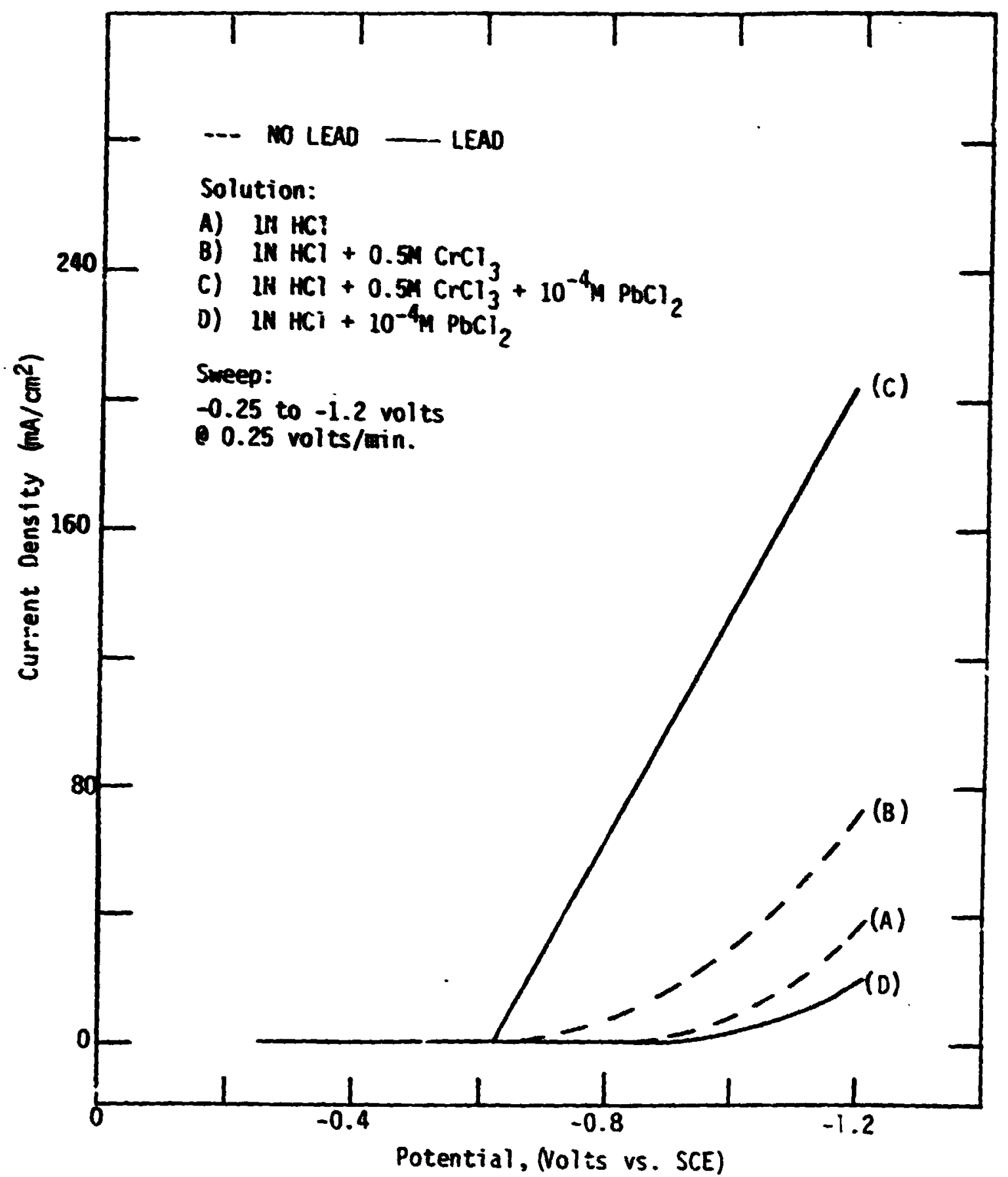

Figure V-3. Hydrogen Evolution and Chromic Ion Reduction on a Carbon Felt Electrode, After Standard

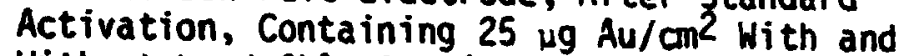
Without Lead Chloride (NASA "0ld" Carbon Felt). 


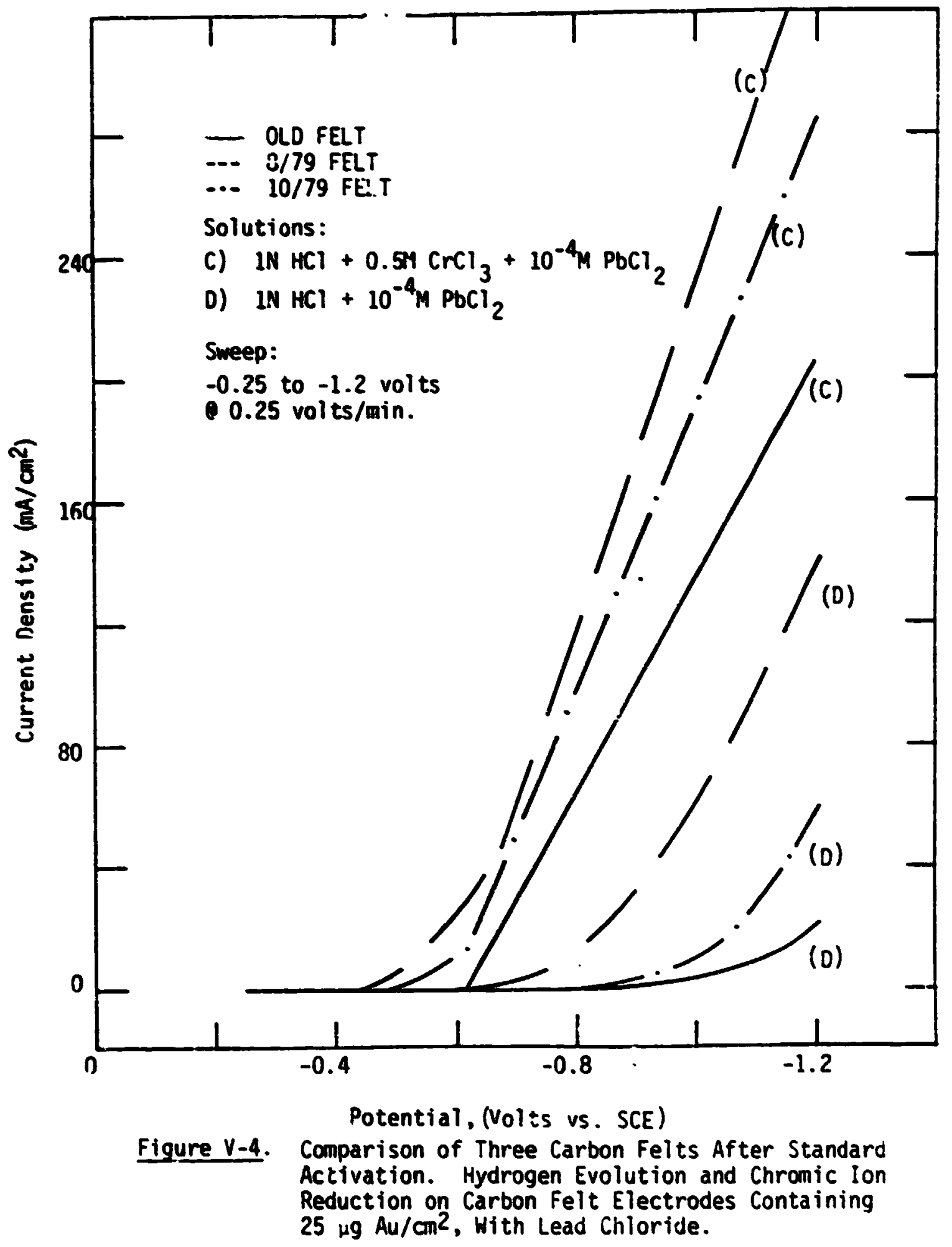


correspondence between measured differences in the physical and surface properties and the differences in electrochemical performance. It appears reasonable, therefore, to use these physical characteristics to evaluate felts.

Preliminary Investigation of Graphite Felt: In view of the variations in production lots of the carbon felt, it is desirable to investigate the suitability and uniformity of graphite felt material for applica:ion in the iron/chromium redox battery. According to the information supplied by the manufacturer (Fiber Materials Inc.), the carbon felt in current use has a carbon content of $\imath 97 \%$, while the graphite felt has a carbon content of $99.9 \%$. It would seem likely that the graphite felt might have greater uniformity and might not require any normalizing procedure which would offset the cost differential. A sample of $\frac{1}{4} "$ graphite felt was soaked in $1.25 \times 10^{-3} \cdot 1$ gold solution, dried and annealed, and character -ed in half-cell experiments in the manner previously described. A comparison of as zived (without any cleaning treatment) graphite felt that is gold/lead catalyz $\mathrm{s}$, and the NASA old felt electrocie is presented in Figure $V-5$. Although these results are derived from an L $_{4}$ thick graphite felt, it is encouraging to note that graphite felt electrodes, without any cleaning or normalizing step, behaved very much like the NASA old felt electrode with good $\mathrm{Cr}$ (III)/Cr(II) activity.and yery high hydrogen polarization.

\section{Improved Catalyzation Processes:}

During the characterization of different felt materials, a most significant difference was the extent of gold pick up by different felts from an aqueous solution

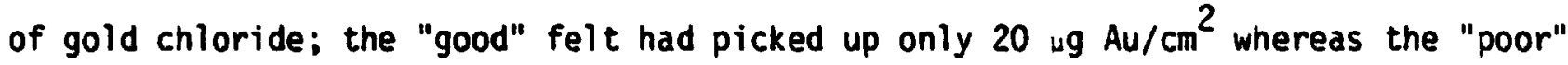

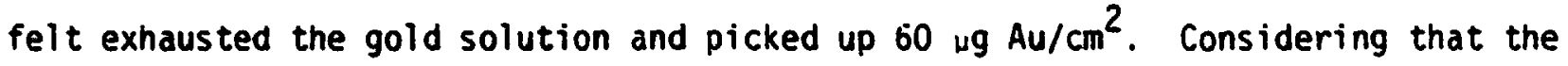
latter felt was the least wettable this gold could not be well distributed. Secondly, it appeared that all the gold chloride had reacted to leave the solution colorless. He believe that the increased gold take up was due to "excessive" reducing groups on the surface of the "poor" $(8 / 79)$ carbon felts. Therefore, oxidizing 


\section{ORIGINAL PAGE IS \\ OF POOR QUALTY}

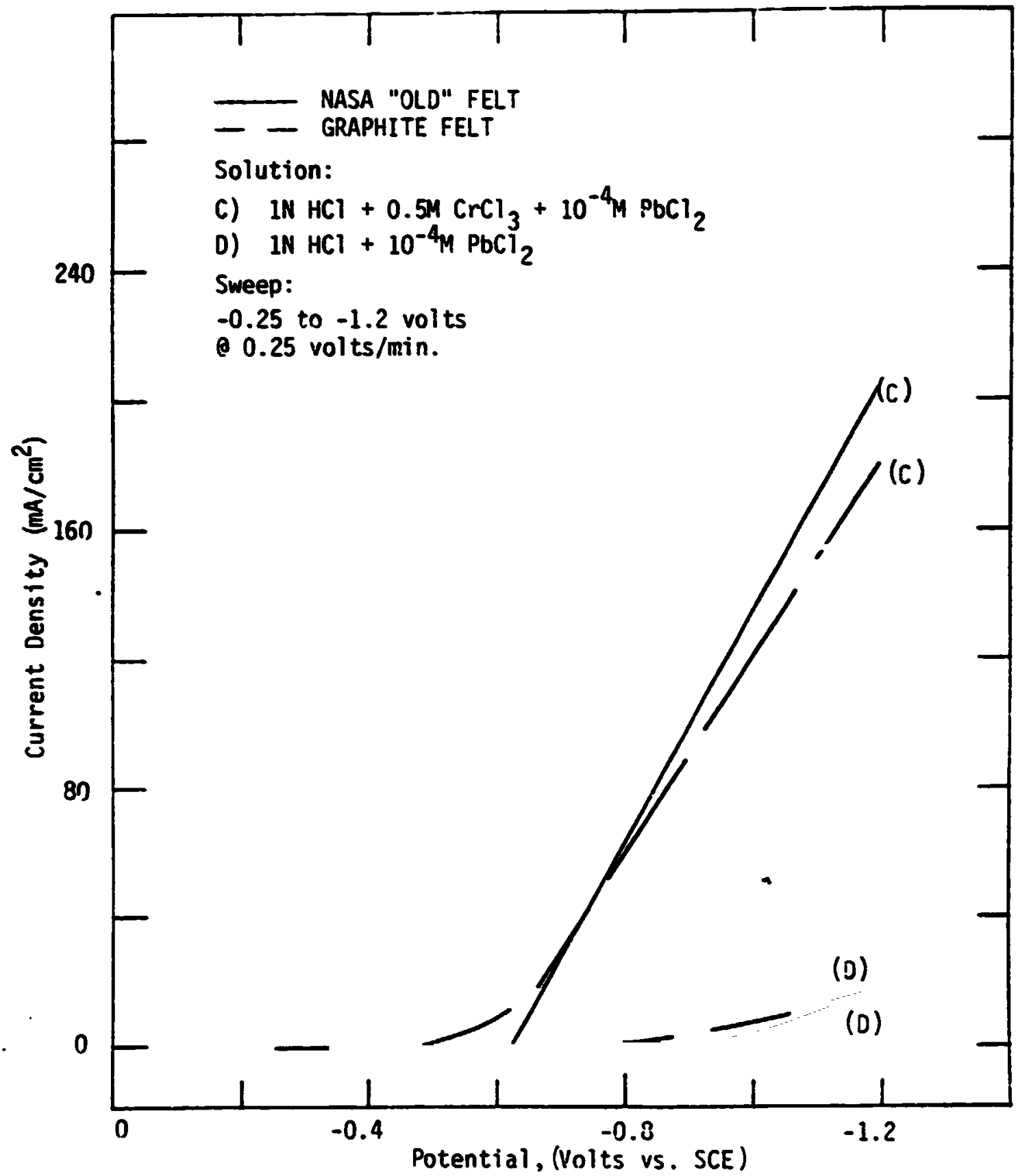

Figure V-5. Comparison of Graphite and Carbon Felts. Hydronen Evolution and Chromic Ion Reduction on the "01d" Carbon Felt (1/8") Electrode and an $\frac{1}{4} "$ Graphite Felt Electrode, (Both Containing $25 \mathrm{ug} \mathrm{Au} / \mathrm{cm}^{2}$ With Lead Chloride. Currents for the Graphite Felt are Compensated for its Double Thickness.) 
treatments such as $\mathrm{H}_{2} \cdot{ }_{2}$, potassium permanganate, shromic acid and nitric acid were tried at Giner, Inc. Simultaneously gas phase treatments, such as air oxidation at $800^{\circ} \mathrm{F}$ and $\mathrm{H}_{2}$ reduction at $1600^{\circ} \mathrm{F}$, were attempted at HASA-LeRC. After initial screening, a nitric acid treatment was further pursued.

\section{Normalization by Nitric Acid}

All three carbon felts (old, 8/79 and 10/79) were soaked in $1 \mathrm{M} \mathrm{HHO}_{3}$ at $60^{\circ} \mathrm{C}$ for 30 minutes, rinsed thoroughly in distilled water, damp dried. and soaked in $1.25 \times 10^{-3}$ if Au ${ }^{+3}$ solution. After the felts had soaked overnight in gold chloride solution, there was only a very slight difference in the appearance of soaking solutions; the solution with the $8 / 79$ felt appeared slightly paler inan the other two.

A second set of carbon felt samples was similarly treated with IM nitric acid but, this time, soaked in a solution containing $7.36 \times 10^{-5} \mathrm{M} \mathrm{Ali}{ }^{+3}$, more dilute than that used in the standard procedure. After overnight soak, the gold containing felts were dried and heated at $260^{\circ} \mathrm{C}$ for $2 \mathrm{hrs}$. Figure $\mathrm{V}-6$ presents polarization curves in a half cell containing $0.5 \mathrm{M} \mathrm{CrCl}_{3}$ in $\mathrm{HCl}$ with and wi: lout $\mathrm{PbCl}_{2}$ solution added. A comparison with figure $\mathrm{V}-4$ shows that a nitric acid precleaning combined with the use of a more dilute gold chloride solution has significantIy decreased the hydrogen evolution of $8 / 79$ and $10 / 79$ felts and the performance characteristics of the three carbon felts are much closer to each other.

A nitric acid soak as a precleaning step was used to oxidize the reducing groups. Such a treatnent in conjunction with the use of more dilute gold solution has shown a significant normalizing effect such that the electrodes from any lot of felt are now similar. Tests at NASA-LeRC ${ }^{(10)}$ on electrodes prepared by nitric acid cleaning of the "poor" (3/79) felt followed by thermal decomposition of $13 \mathrm{~g} \mathrm{gu} / \mathrm{cm}^{2}$ onto the surface proved satisfactory in lab cells but not in larger cells. Clearly, the results outained with this normalizing process are significant but insufficient improvements. 


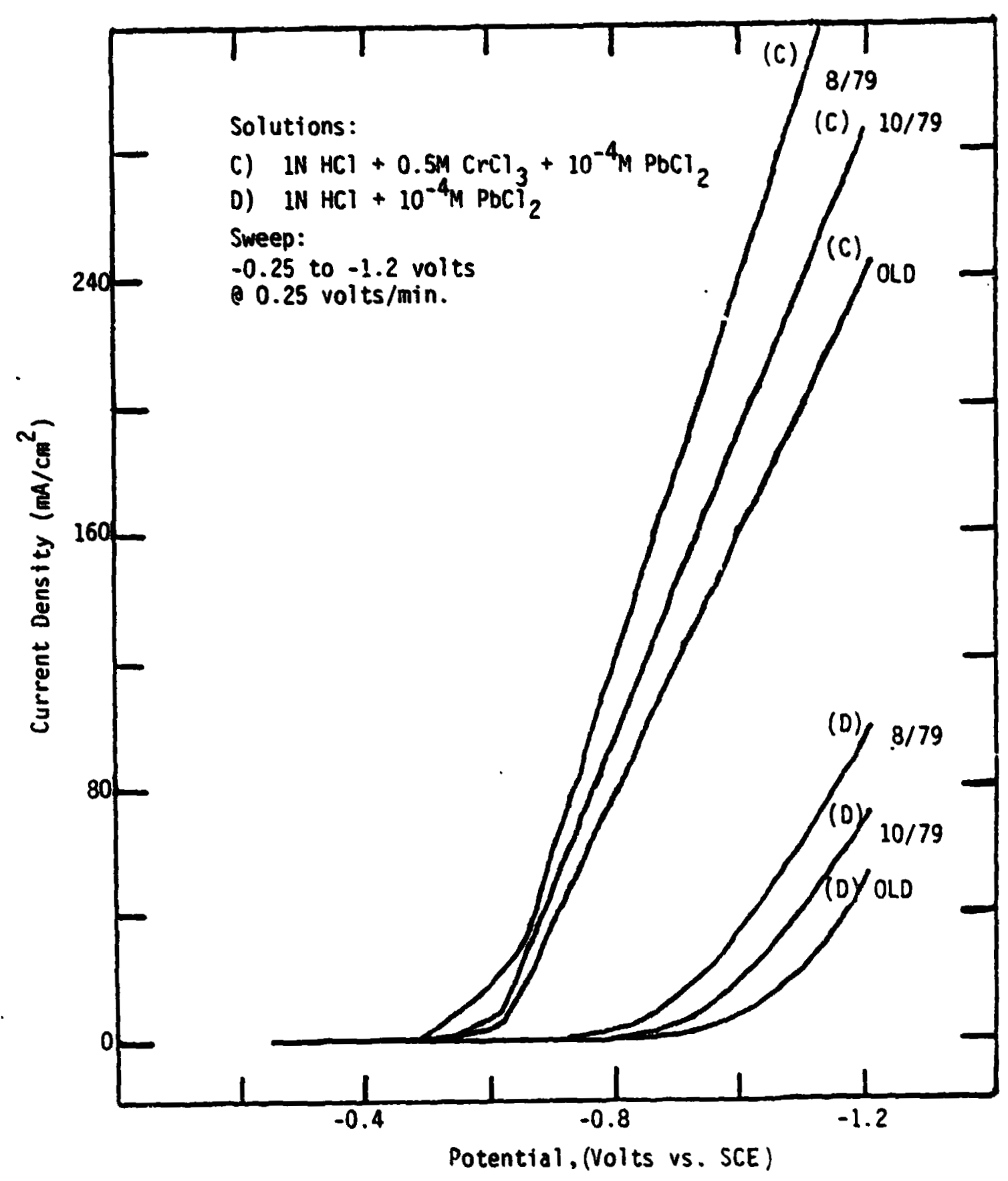

Figure V-6: A Comparison of Three Carbon Felts After $\mathrm{HNO}_{3}$ Norma If zation Treatment. Hydrogen Evolution and Chromic Ion Reduction or Carbon Felts Containing $13 \mu \mathrm{Au} / \mathrm{Cm}^{2}$, With Lead Chioride. 


\section{Alcohol Assisted Gold Impregnation:}

A nitric acid soak as a possible normalization treatment for carbon felt shoived significant but inadequate improvements. Apparently, the variance in the conditions of the felts from different lots exceeded the normalization effect of this treatment. In our opinion, it was necessary to achieve (a) complete wetting of the felts and (b) uniform distribution of highly dispersed gold.

Alcoho? is an excellent wetting agent for carbon and graphite materials. In an effort to uniformly distribute gold on a carbon felt electrode, a soaking solution containing isopropanol was made up with $1.25 \times 10^{-3} \mathrm{M} \mathrm{HAuCl}_{4} \cdot 3 \mathrm{H}_{2} \mathrm{O}$ in a $50 \%$ water 50\% isupropanol (by volume) mixture. A sample of the old felt was soaked in this solution. The rest of the steps (drying and heating at $260^{\circ} \mathrm{C}$ for $2 \mathrm{hrs}$ ) of the standard procedure were used and the resulting electrode was tested by the linear sweep voltarmetry technique. As expected, the results as presented in Figure $l^{\prime}-7$ indicated increased gold take-up.

As a result of the above work, further experiments were done at NASA-LERC with dilute gold chloride concentrations in an alcohol/water mixture in conjunction with the use of $\mathrm{KOH}$ as a precieaning step. This work resulted in a process that gave the best electrochemical characteristics observed to date -- very little hydrogen evolution and very high rates for chromium redox reaction. This process will be called alcohol assisted and is described in Appendix B. A comparison of hydrogen evolution characteristics of the electrodes prepared by different ter.hniques developes in this program is given in Figure $v-8^{(10)}$.

The improved catalyzation technique which involves an alcohol assisted gold impregnation and a precleaning step using $\mathrm{KOH}^{(11)}$ produced electrodes which do not evolve measureable amounts of hydrogen until the cell is 95: fully charged. In acdition, these electrodes snow excellent performance on discharge. An important aspect of this method of preparation is that it produces well behaved electrodes from most lots of felt tried so far, so that characterization or the felt is no longer a major problem. These procedures seem entirely satisfactory for small cells 


\section{ORIGINAL PAGE IS \\ OF POOR QUALITY}

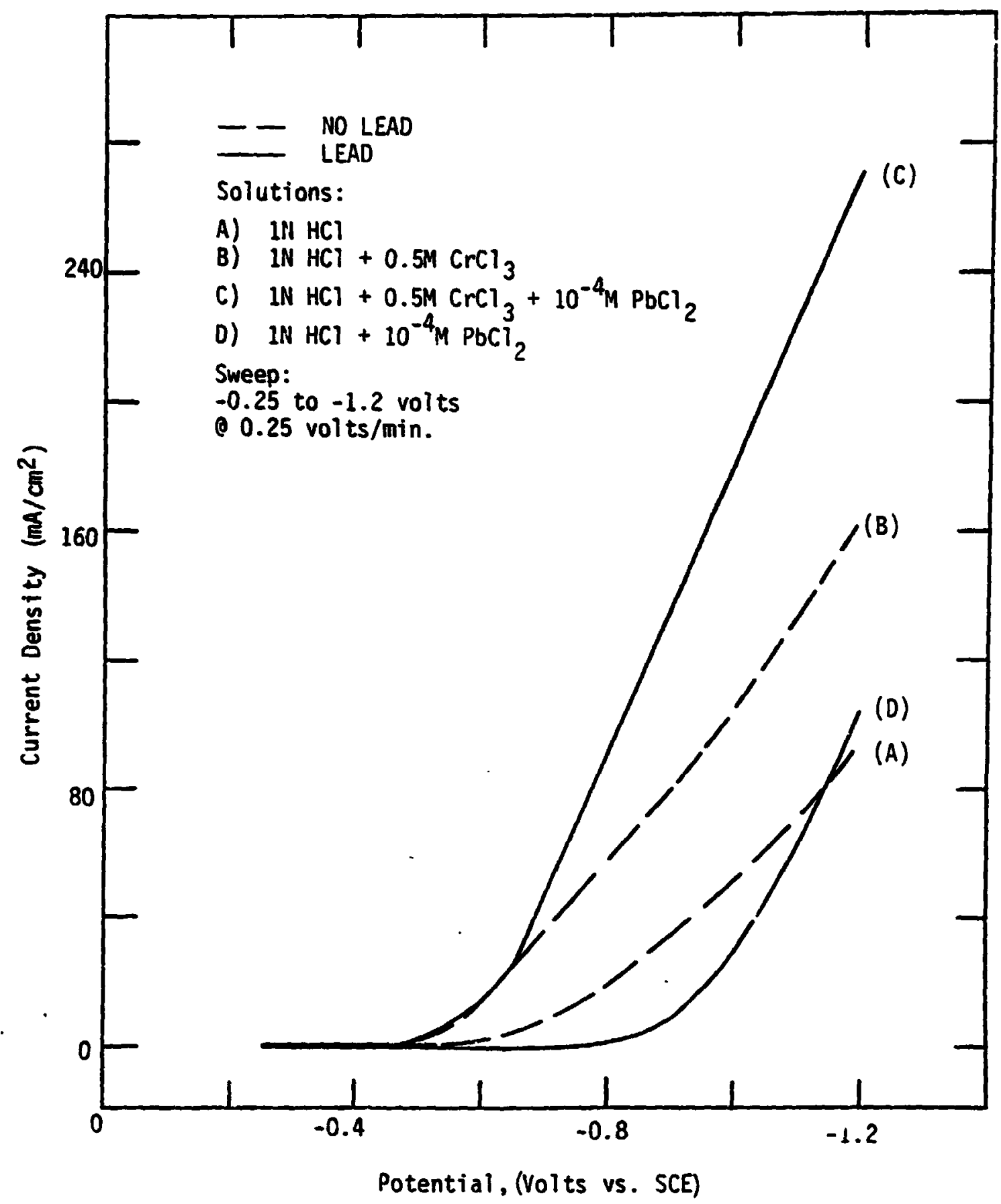

Figure V-7: Effect of Aicohol Assisted Gold Impregnation. Hydrogen Evolution and Chromic Ion Reduction on "O1d" Carbon Felt Containing Gold, With and Without Lead Chloride. 


\section{ORIGINAL PAGE IS
OF POOR QUaLITY}

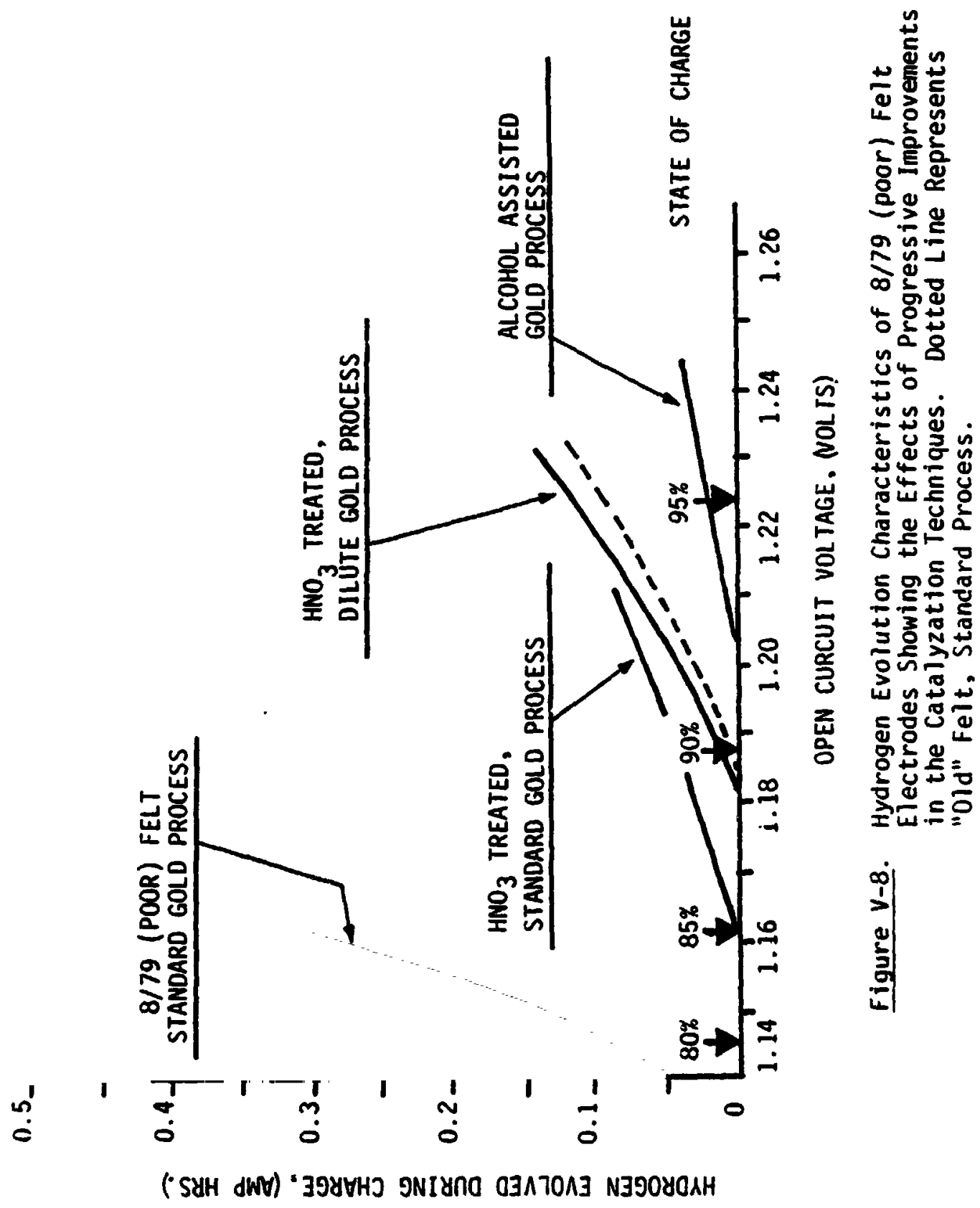


and large single cells(12). Further refinements will be needed, however, to achieve second order improvements such as to minimize the blue hysteresis effects. 
NASA-LeRC has gained considerable practical experience with the performance of lead/gold electrodes in complete single cells as well as in stacks of cells. Congruently, many questions have arisen regarding performance variability. This has been attributed to non-uniformity in the felts and in the gold deposition process. During the course of this proc ram, a systematic study of lead/gold electrocatalysts was initiated with the goal of advanced development of the chromium redox electrode. The objectives of this study are:

(a) The development of reliable, quantitative screening methods for quality assurance and control of flow cell electrodes.

(b) Determination of carbon felt characteristics relevant to performance.

(c) Determination of methods of applicat. on of gold and lead to achieve uniform and reproducible performance.

(d) Establishment of a baseline for gold/lead performance to facilitate optimization and for comparison with alternative electrocatalyst systems.

(e) Optimization of the gold/lead ratio and loading for maximum performance.

(f) Investigation of possible reactivity differences between chromium complexes which may relate to hysteresis effects.

This work was star $-j$ under the present contract and is to be continued under a follow on contract (NASA Contract DEN3-198).

Cyclic voltammetry is being developed as a screening method because it affords the opportunity to study $\mathrm{Cr}$ (III) reduction and $\mathrm{Cr}$ (II) oxidation in a single experiment using Cr(III) electrolyte. All the information needed, incluciing kinetic parameters, can be derived, in principle, from cyclic voltammetric data. However, extracting the information from the data is a challenging problem.

The experimental procedure is essentially similar to the one used for linear sweep voltamnetry except that a triangular sweep is used. Improvements in technique will be incorpo:ated in the follow on contract. First, NASA-LeRC has 
suggested $(10)$ a method for mounting felt electrodes, with a spring clip masked with wax, whish does not involve compression of the felt. Second, electronic iR compensation will be used in the future experiments.

A. Hydrogen Fvolution and Lead Deposition on Carbon

As was the case in the linear sweep voltammetry, cyclic voltarmetry shower very little hydrogen evolution on bare carbon felt in $1 \mathrm{~N} \mathrm{HCl}$. The solution was made to $\mathrm{In}^{-3} \mathrm{M}$ in $\mathrm{PbCl}_{2}$ by adding a measured amount of saturated lead chloride solution into the cell. The working electrode was held at $0 \mathrm{mV}$ (SCE) where no bulk lead deposition should occur. A multi-cycle voltammogram was then obtained, first, between $0 \mathrm{~V}$ and $-1.0 \mathrm{~V}$ at a scan rate of $10 \mathrm{mV}$. Very well defined lead deposition and lead deplating peaks were obtained. As shown in Figure $V I-i$, the anodic branch of the curve was investigated up to $+600 \mathrm{mV}$ (SCE), but no evidence for underpotential deposited lead on carbon was obtained.

B. Hydrogen Evolution and Lead Deposition on Gold on Cartion

Figure VI-2 illustrates the hydrogen evolution reaction in $1.2 \mathrm{M} \mathrm{HCl}$ at a gold on carbon felt electrode $\left(13 \mu \mathrm{g} \mathrm{Au} / \mathrm{cm}^{2}\right)$ prepared by the alcohol assisted method. Although gas bubbles seemed to cling tenaciousiy to the felt, no trace of $\mathrm{H}_{2}$ oxidation was found in the potential range of this experiment.

It can be seen that the hydrogen evolution current starts to become significant at about $-600 \mathrm{mV}$ versus SCE which is about the potential at which the chromium electrode operates. It was attempted to suppress this hydrogen evolution by adding $\mathrm{PbCl}_{2}$ to the electrolyte in trace amount. The solution was made $4.8 \times 10^{-5} \mathrm{M}$ in $\mathrm{Pb}$ (II) which corresponds to $100 \mu \mathrm{g} \mathrm{Pb} / \mathrm{cm}^{2}$ felt. The working electrode was potentiostated for ten minutes at $-618 \mathrm{mV}$ (SCE) (while bubbling $\mathrm{N}_{2}$ through the solution) so that the deposition of lead could proceed. The multi-cycle voltammogram (still solution) shown in Figure VI-3 was than obtained. The hydrogen evolution is reduced by an order of magnitude compared to Figure VI-2. It is important to note that as successive cycles were performed, the amount of lead deposited cecreased, but the hydrogen evolution reaction was unchanged. Apparently during 


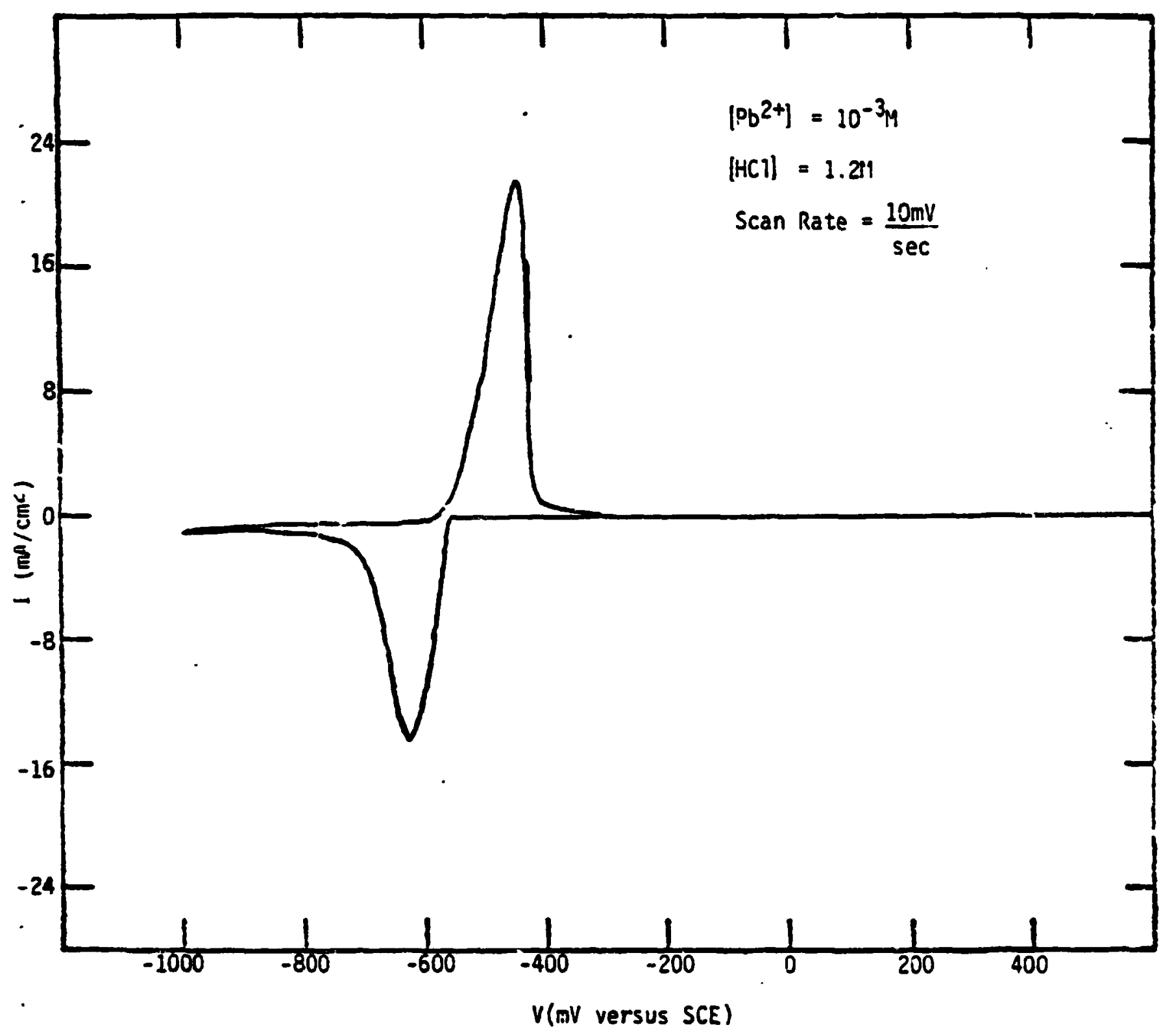

Figure VI-1: Steady-State Voltammogram of Lead Deposition-Dissolution Reaction at Carbon Felt 


\section{original page is \\ OF POOR QUALTTY}

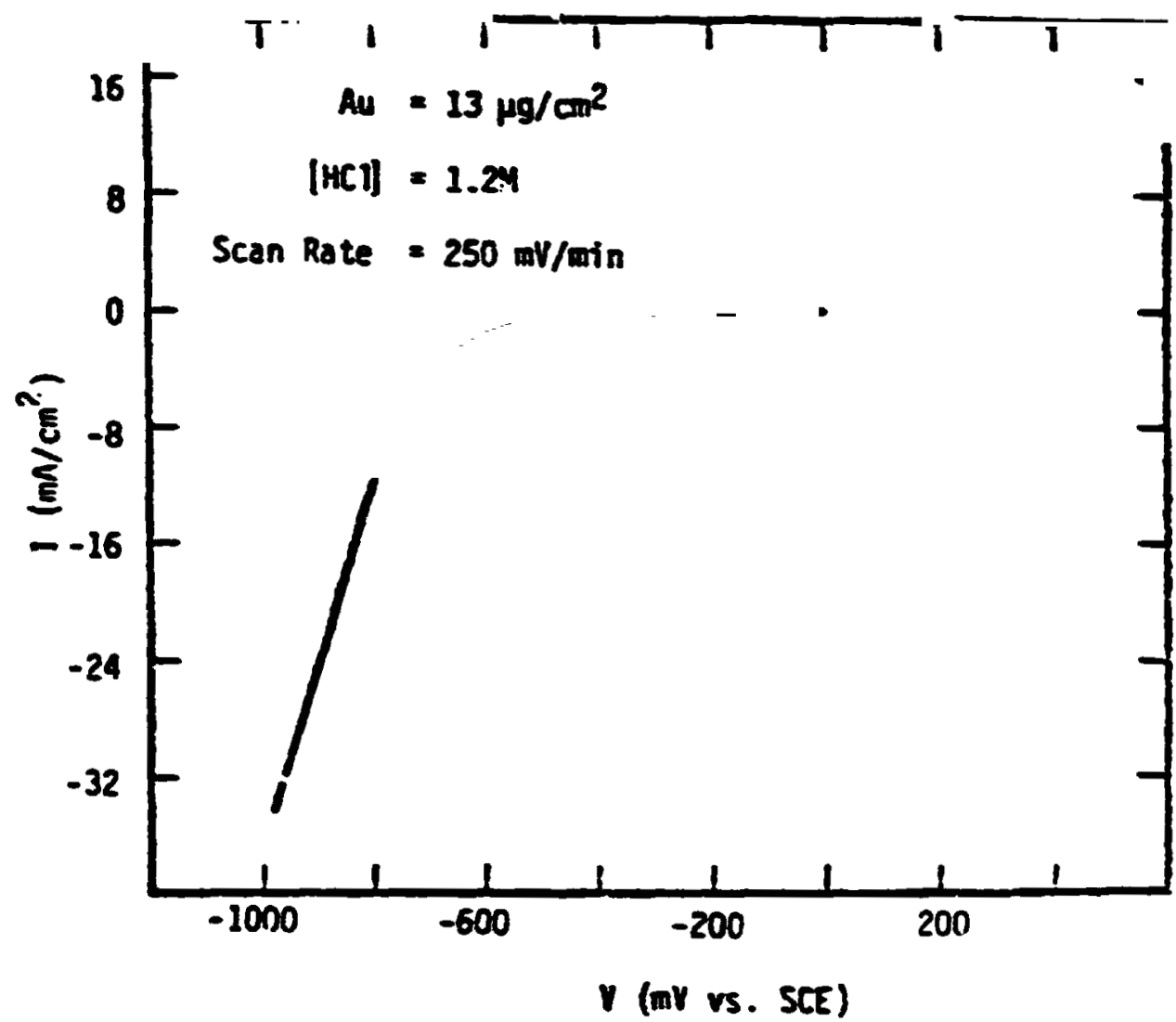

Figure VI-2: Hydrogen Evolution at Gold on 1/8" Carbon Felt Électrode 


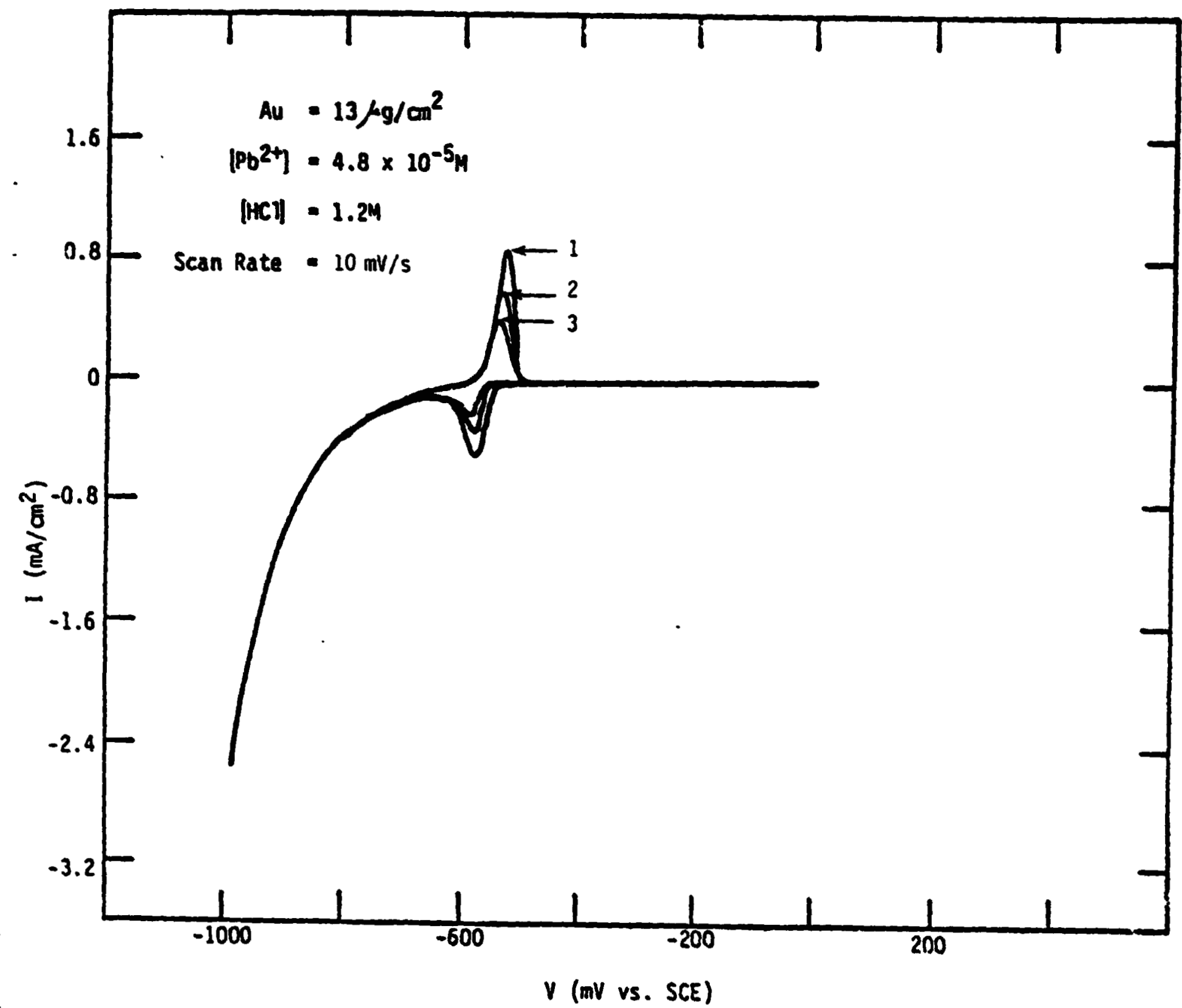

Figure VI-3: Lead Deposition-Dissolution at Gold on Carbon Felt. 
cycling, the $\mathrm{Pb}(\mathrm{II})$ ions slowly diffused away from the felt because the bulk concentration of $\mathrm{Pb}^{2+}$ is so low. The amount of lead corresponding to the smallest stripping peak in Figure $V I-3$ is about $3 \mu \mathrm{g} / \mathrm{cm}^{2}$ or $1.5 \mu \mathrm{g}$ for the $0.5 \mathrm{~cm}^{2}(8 \mathrm{~mm}$ diameter) electrode used. It can be concluded that only trace, even submonolayer anount of lead is sufficient to eliminate hydrogen evolution on gold. Once again, we found no evidence of under-potential deposition of lead on gold in this experiment.

The absence of any UPD (or adatcms of) lead is contrary to the works of Adzic, et al ${ }^{(13)}$ and McIntyre, et al ${ }^{(14)}$ who found very strong evidence of UPD lead on gold in perchloric acid and $\mathrm{KOH}$, respectively; both these electrolytes are noncomplexing with respect to lead. In contrast, our experiments are in $\mathrm{HCl}$. Lead complexes with chloride ions and perhaps does not undergo LPD.

C. Chromic Ion Reduction on Carbon, Lead and Gold/Lead

1. Carbon

A plain felt electrode was cycled in $0.2 \mathrm{M} \mathrm{Cr}^{+3}$ solution. As shor in Figure VI-4, very small amounts of $\mathrm{Cr}$ (III) were reduced. Essentially no $\mathrm{Cr}$ (II) was oxidized in the practical range of battery operation. At very high polarizations, however, $\mathrm{Cr}$ !II' does oxidize on carbon but in a complex manner which is not understood. The multiple peaks are probably due to the inhomogeneous surface of carbon felt.

\section{Lead on Carbon}

Following the scan of Figure $\mathrm{VI}-4$, a measured amount of $\mathrm{PbCl}_{2}$ was added to the electrolyte. The resulting solution was $\left(0.2 \mathrm{M} \mathrm{CrCl}_{3}+10^{-4} \mathrm{M} \mathrm{PbCl}_{2}\right)$ in $1.2 \mathrm{M} \mathrm{HCl}$. A study state cyclic voltammogram is shown in Figure VI-5. At $-600 \mathrm{mV}$, coincident with lead deposition, we saw large amounts of $\mathrm{Cr}(111)$ reduction. This very clearly established that bulk lead is an active catalyst for chromium reduction. Essentially reversible oxidation of chromium occurred on lead surface but coincident with lead dissolution there was a precipitous drop in the chromium oxidation reaction. Carbon is totally inactive for $\mathrm{Cr}(11)$ oxidation at this potent1al. At higher overvoltages once again chromium oxidation proceeded in a complex manner. The essential features of chromium oxidation peaks in this higher potential range 
ís

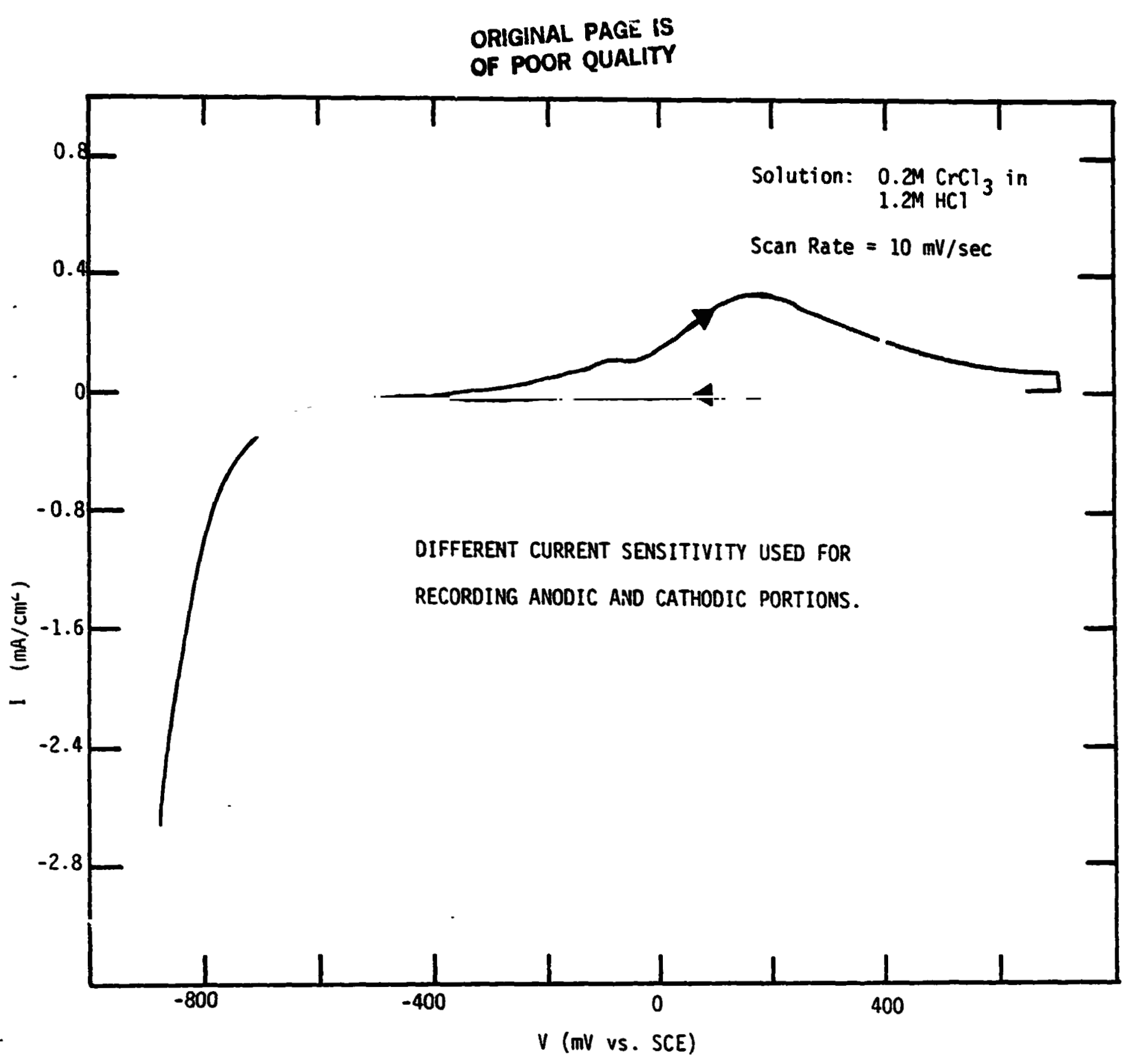

Fijure VI-4: Single Sweep Cyclic Voltanmogram of Chromic Chloride/Chromous Chloride Reaction on Bare Carbon Felt (No Gold, No Lead). 


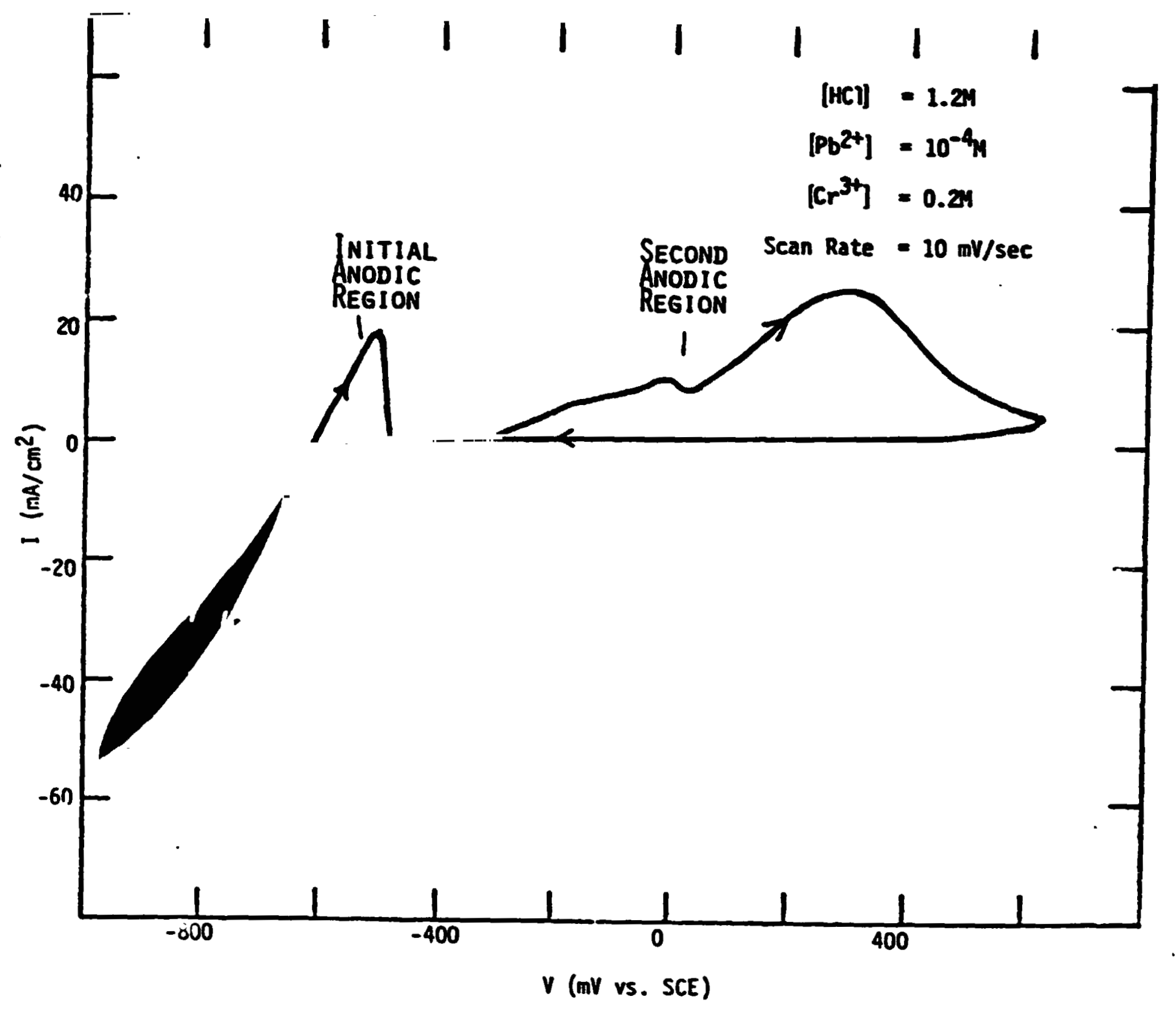

Figure VI-5: Steady State Vol tammogram of Chromic Chloride/Chromous Chioride Reaction at Lead on Carbon Felt Electrode. 
remained the same as that on plain carbon felt.

3. Gold-Lead on Carbon

Figure VI-6 represents our first attempt to study the $\mathrm{Pb} / \mathrm{Au}$ on carbon electrode in $\mathrm{Cr}(\mathrm{III}), \mathrm{HCl}$ electrolyte. The cycling of Figure $\mathrm{VI}-3$ was continued until almost no noticeable amount of lead was being stripped off the electrode. At this point, the hydrogen evolution was only slightly increased over tha: oictured in Figure VI-3. While the working electrode was at open circsit, enough $\mathrm{CrCl}_{3} \cdot 6 \mathrm{H}_{2} \mathrm{O}$ was added to the solution to give $\left(0.2 \mathrm{M} \mathrm{CrCl}_{3}+4.8 \times 10^{-5} \mathrm{M} \mathrm{PbCl}_{2}\right)$ in $1.2 \mathrm{~N} \mathrm{HCl}$. A multi-cycle voltammogram between $0 \mathrm{~V}$ and $-1.0 \mathrm{~V}$ (SCE) was then obtained. Figure VI-6 is the fourth cycle. The observed cathodic currents must be essentially due to hydrogen evolution and $\mathrm{Cr}$ (III) reduction since the lead deposition currents are very small. It rould be very helpful to know the fraction of current due to each of these reactions as a function of potential, but the data are presently insufficient. One would not predict from a comparison of Figure VI-3 and Figure VI-6 that the sharp rise in current following the cathodic peak is purely hydrogen evolution. The residual cathodic current observed for lead deposition reaction suggests that the sharp rise might be hydrogen evolution superimposed on a $\mathrm{Cr}$ (III) reduction limiting current. Another possibility could be $\mathrm{Cr}$ (III) catalyzed hydrogen evolution. This could be caused by adsorption of $\mathrm{Cr}$ (III) on gold so that the coverage of gold by lead is lessened. These matters warrant further investigation.

Another suzzling feature of Figure VI-6 is the double anodic peak. The oxidation of labile $\mathrm{Cr}$ (II) species at an inert electrode is expected to - ive only one peak (15). The second peak does not seen to be due to oxidation uf $\mathrm{Cr}$ (II) on carbon because: a) carbon is a poorer catalyst than lead/gold, and b) the area of carbon is much greater than that of lead/gold and essentially invariant. Hiore research would be needed in order to understand this double peak behavior.

Figure VI-7 is a multi-cycle voltammogram (at $10 \mathrm{mV} / \mathrm{sec}$ scan rate) of the $\mathrm{Cr}(\mathrm{III} / \mathrm{HCl}$ electrolyte obtained subsequent to holding the potential of the working electrode at $-620 \mathrm{mV}$ for a short time. The current at certain potentials is 
ORIGINAL PAGE IS

OF POOR QUALITY

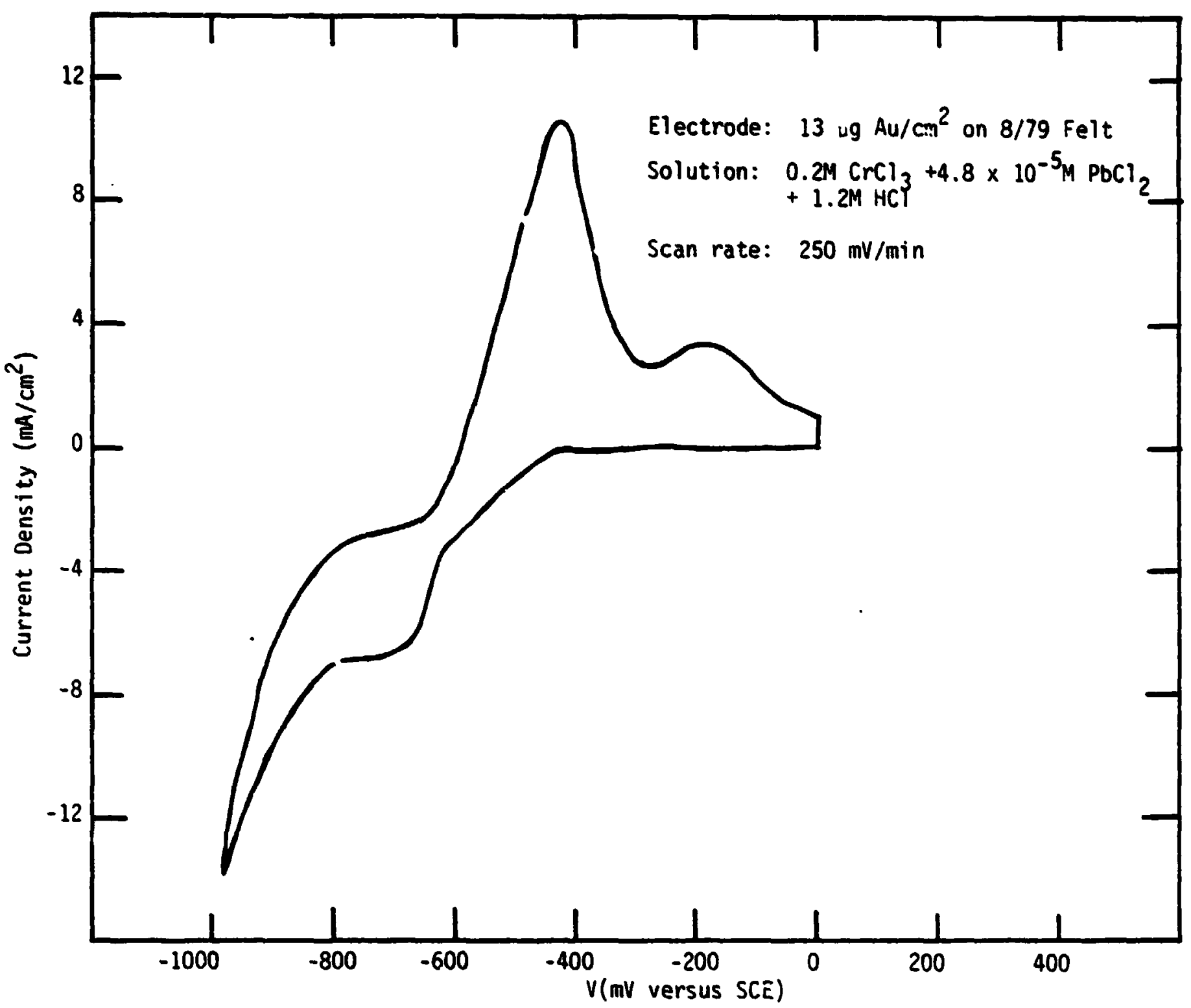

Figure VI -6: Single-Sweep Cyclic Voltammogram of Chronic Chloride/Chromous Chloride Reaction at Lead/Gold on 1/8" Carbon Felt Electrode With $13 \mu \mathrm{g} \mathrm{Au} / \mathrm{cm}^{2}$.

-46 . 
i

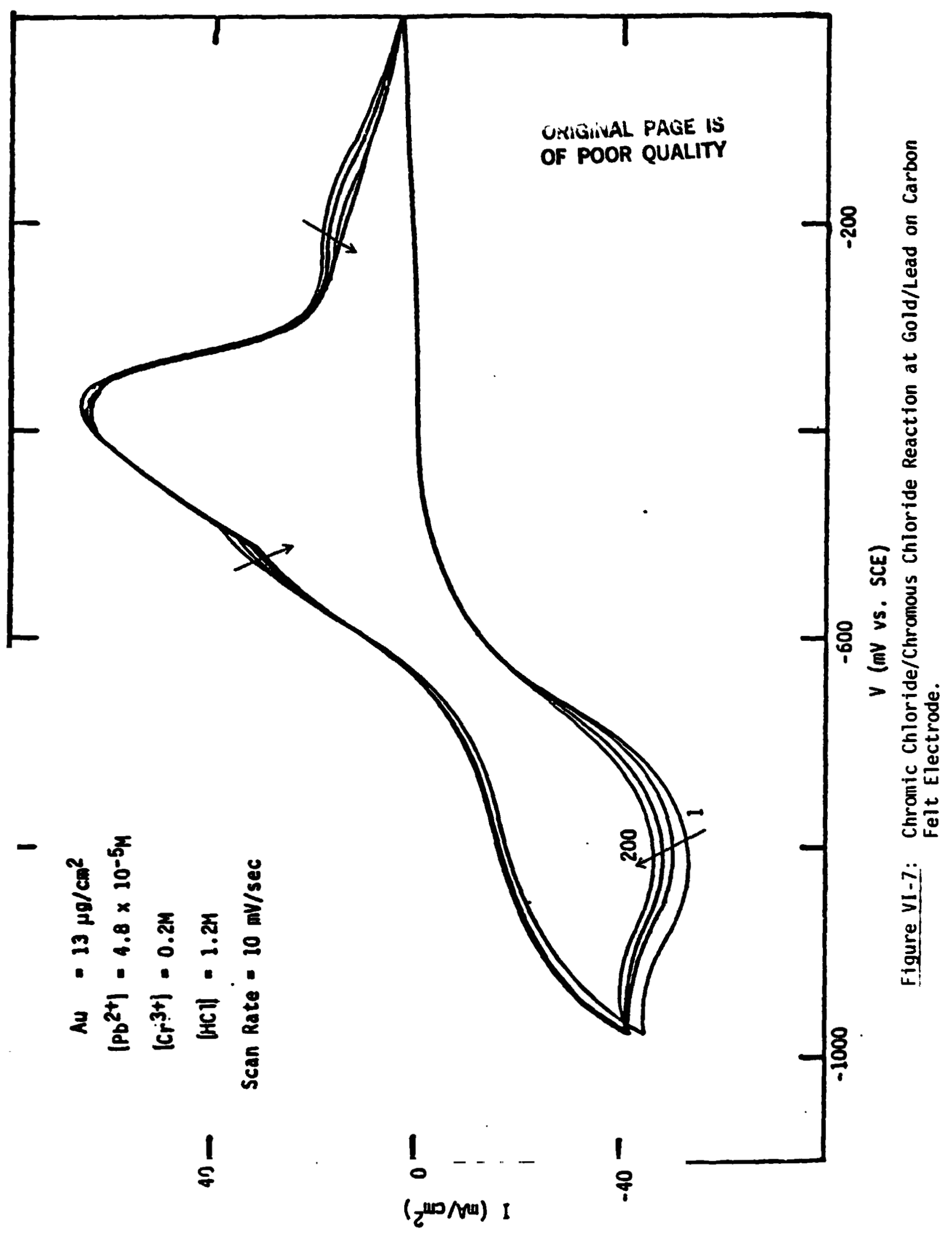


seen to decrease slightly on successive cycles. Note that on each cycle, the dissolution potential of lead is exceeded. Mevertheless, extended cycling experiments (>200 cycles) showed that although subtle changes in electrode behavior are possible, the ability of $\mathrm{Au} / \mathrm{Pb}$ on carbon felt electrodes to reduce $\mathrm{Cr}$ (III) and oxidize $\mathrm{Cr}$ (II) is maintained. The unexplained double peaks on $\mathrm{Cr}$ (II) oxidation portion appear to have some correspondence to the cycling. Further work is essential to understand this phenomena. 
VII. BISIUTH: AN ALTERNATE ELECTROCATALYST FOR CHROHIC CHLORIDE/CHROMOUS CHLORIDE

Although the lead/gold system is adequate at the present time, it would be highly desirabl ? to deveiop an alternative electrocatalyst for the chromium redox reaction that is even more active, has a higher overvol tage for hydrogen evolution and is stable (does not plate and deplate). Therefore, it was considered worthwhile to conduct an exploratory investigation in this program. Under the follow-ud contract we expect to do a somewhat more quantitative investigation.

The feasibility of using bismuth for electrocatalysis of the $\mathrm{Cr}$ (III)/Cr(II) redox couple was investigated by the technique of potentiodynamic sweep voltarmetry in a half cell. Bismuth is an attractive material. It is thermodynamically stable at the potentiais of interest, and it was shown to have a relatively high hydrogen overvol tage.

\section{A. Stability:}

An experiment was performed in which about $10^{-4} \mathrm{M} \mathrm{Pb}^{2+}$ was added to a solution containing about $10^{-4} \mathrm{M} \mathrm{Bi}^{3+}$ in $1 \mathrm{~N} \mathrm{HCl}$. After a sweep from 0.0 to -1.2 volts was performed, a sweep was performed from -1.2 volts to about +0.5 volts (SCE), and an I vs. E curve from -0.6 voits to +0.5 volts was recorded, which is shown in Figure VII-1. Two anodic deplating peaks are present. Peak (1) is the lead deplating peak which begins at a potential of about -0.55 volts, while peak (2) is the bismuth deplating peak which begins at about -0.17 volts vs. SCE. The results obtained here indicate a significant advantage in the more positive deplating potential of bismuth as compared with that of lead. This is consistent with Pourbaix ${ }^{(16)}$ and warranted further investigition.

B. Bismuth on Carbon Electrode:

Linear sweep voltammetry was performed with the oid carbon felt sample in a solution of $0.5 \mathrm{M} \mathrm{CrCl}_{3}$ and $10^{-4} \mathrm{M} \mathrm{BiCl}_{3}$ in $\mathrm{IN} \mathrm{HCl} \mathrm{(Solution} \mathrm{E}$ ). The electrode was rinsed with distilled water and a solution of fresh $1 \mathrm{~N} \mathrm{HCl}$ with $10^{-4} \mathrm{M} \mathrm{BiCl}_{3}$ (Solution F) was sul, cituted and the sweep repeated. The results are given in 


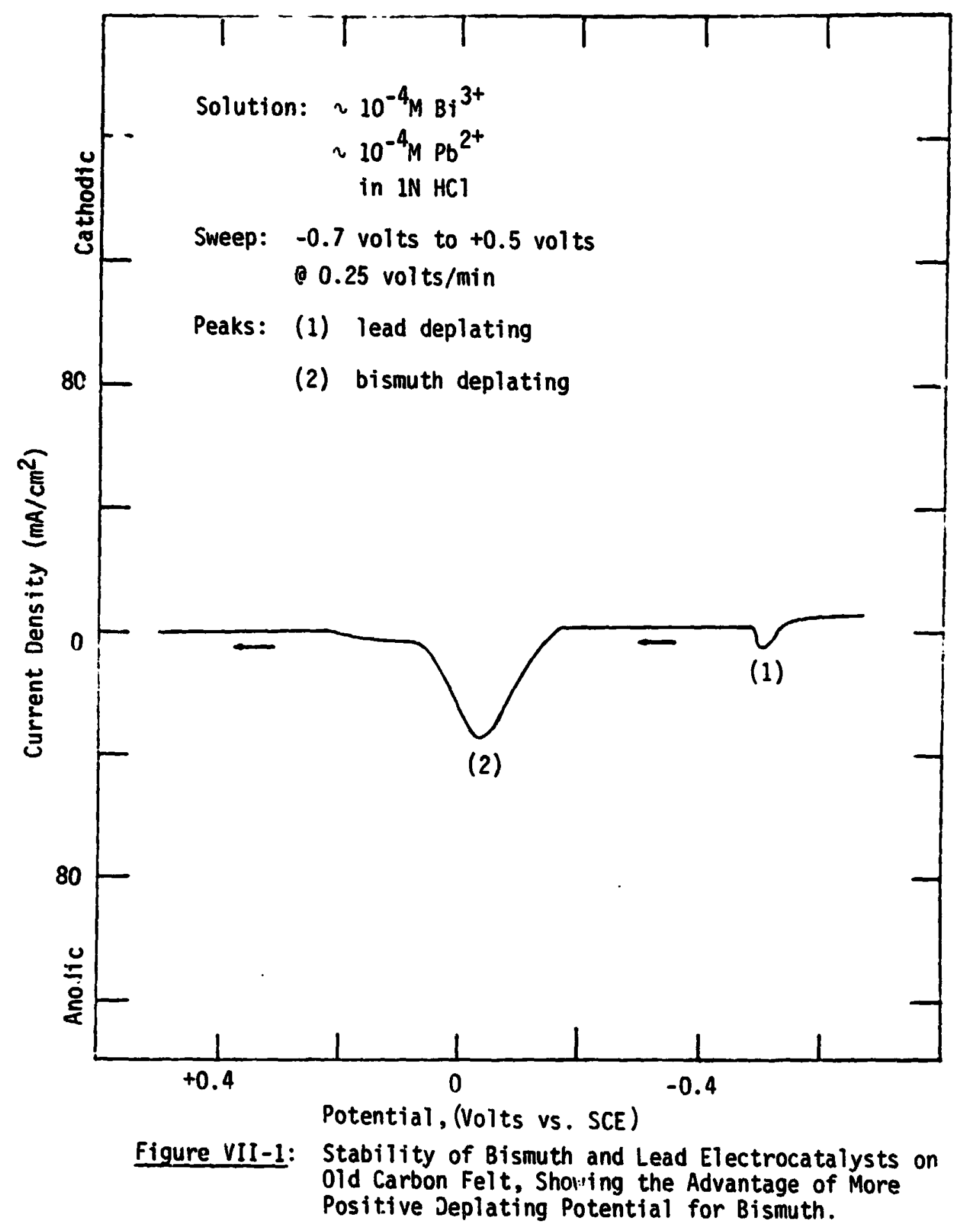


Figure VII-2 along with the results of similar experiments with $\mathrm{PbCl}_{2}$. We can see that $\mathrm{Pi}$ on carbon electrode has $\mathrm{Cr}$ (III) reduction activity that is similar to $\mathrm{Pb}$ on carbon. Hydrogen evolution on the bismuth electrode is, however, greater than on the lead electrode.

C. Gold/Bismuth Electrode:

This electrode is anaiagous to the sold/lead electrode in that gold was thermally deposited and Bi(III) ions were added to the electrolyte. The cyclic voltammogram shown in figure VII-3 was started at $-300 \mathrm{mV}$ (SCE) and reversed at -1.0V. The reverse sweep was interrupted at about $-300 \mathrm{mV}$ and the current allowed to go to zero. The suale was expanded, and an anodic stripping voltamogram was obtained. Only $13 \%$ of the initial $50 \mathrm{\mu g}$ bismuth in solution was stripped from the electrode. The greater stability of bismuth compared to lead may have some practical applications (e.g. making assembly-ready electrodes). The possibility of determining directly the amount of bismuth responsible for a certain $\mathrm{Cr}($ III)/Cr(II) polarization curve may ease the task of optimizing this system. Judging from the $\mathrm{Cr}(\mathrm{II})$ oxidation peak significant amounts of $\mathrm{Cr}$ (III) reduction is apparent. However, the lack of a well Jefi.ied reduction peak suggests overlap with hydrogen evolution. Further investigations with higher bismuth loading are recommerided.

During both these experiments we note that on bismuth electrocatalyst the onset of $\mathrm{Cr}$ (III) reduction appears to be at $\sim-450 \mathrm{mV}$ compared to $\sim-600 \mathrm{mi}$ on 1 ead. A reexamination of figures IV-7 \& IV-8 of our previous report ${ }^{(4)}$ also show similar effects with bismuth. Ho definite conclusions can be made regarding the cause of this effect. 


\section{ORICINAL PACE IS OF POOR QUALTY}

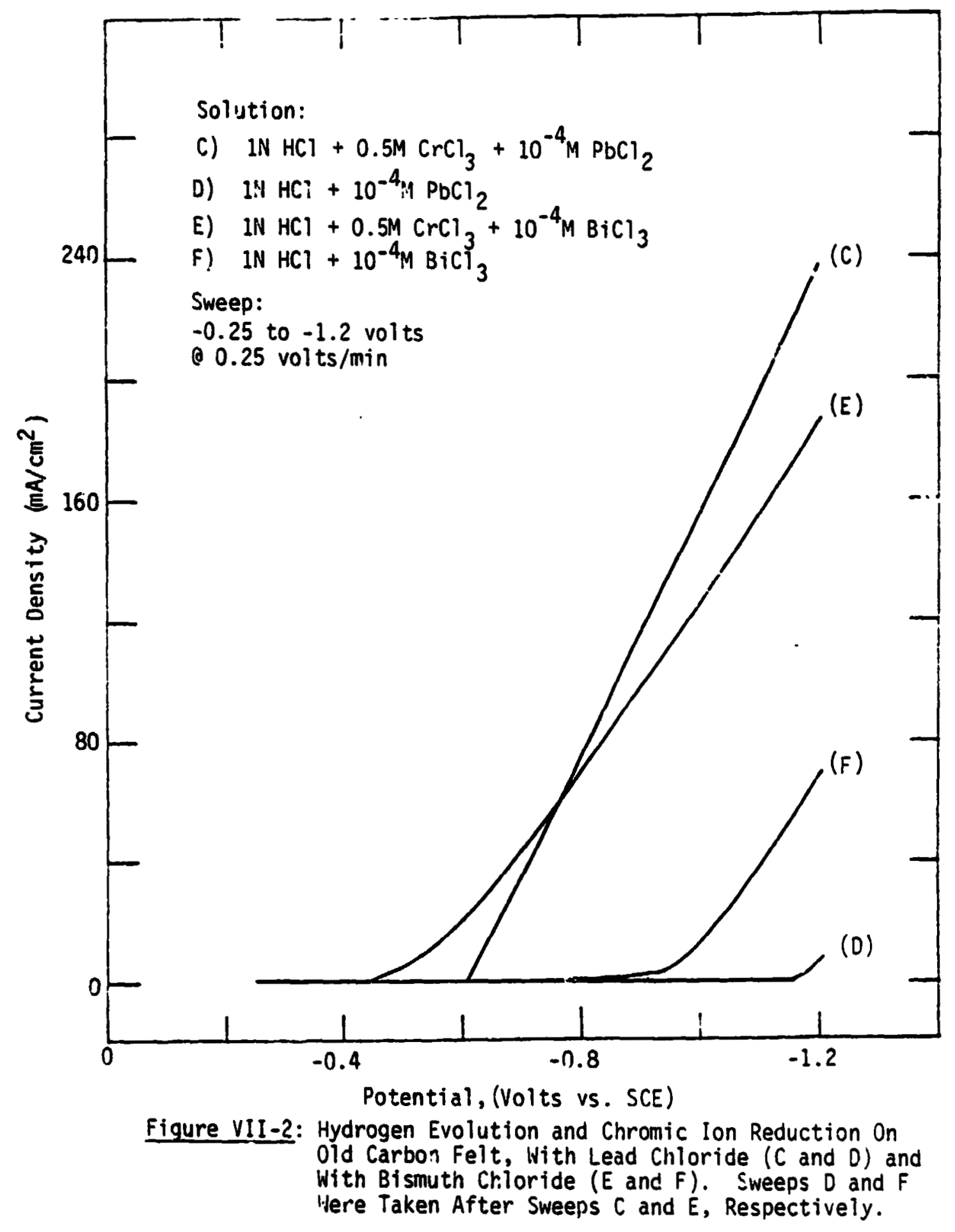




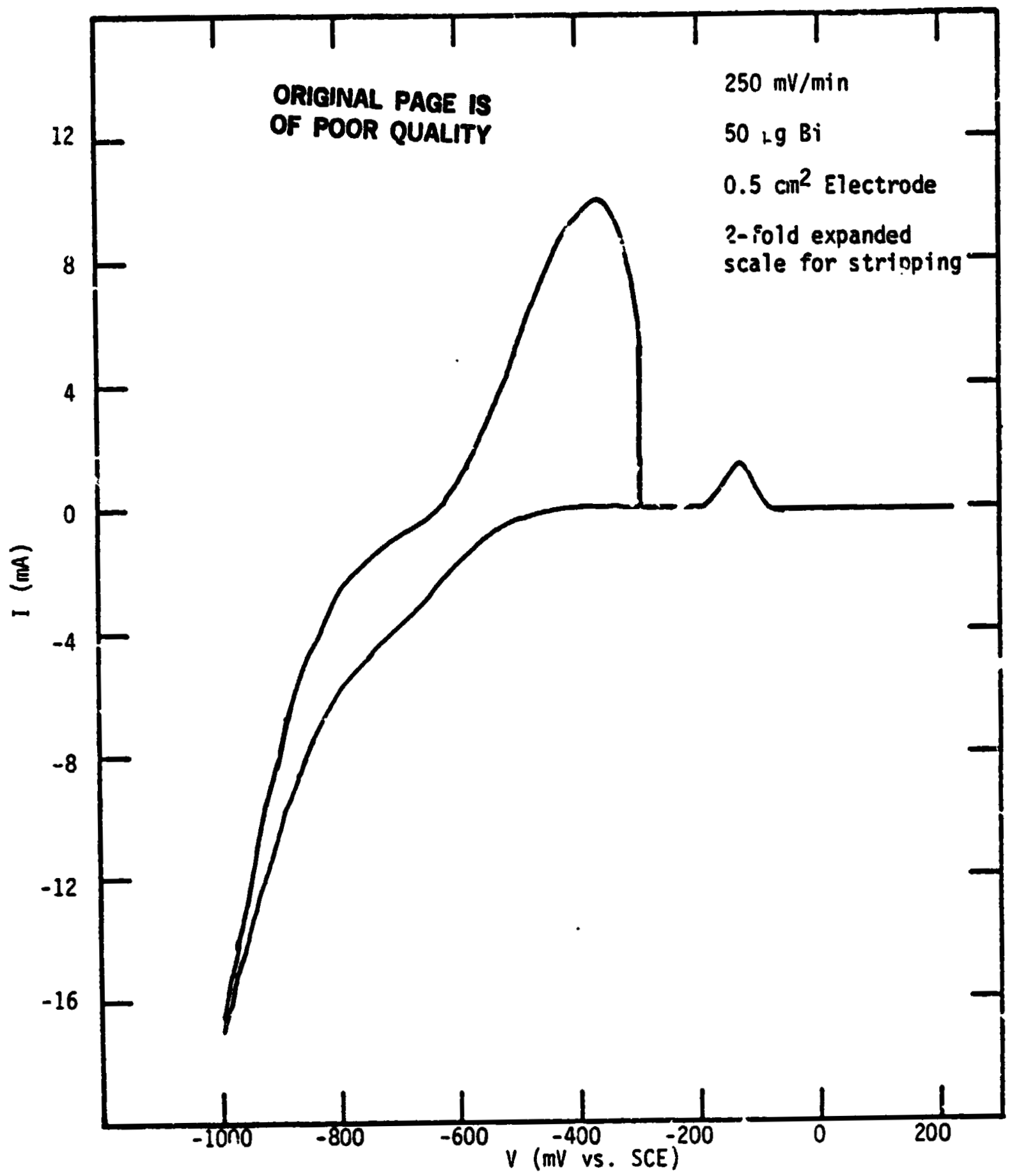

Figure VII-3: Gold/Bismuth Electrode in 0.2M Chromic Chloride, 1.2M Hydrochloric Acid 


\section{SIGNIFICANT RESULTS AND CONCLUSIONS}

1: It is confirmed thist trace amounts of gold $\left(10-25 \mu \mathrm{g} \mathrm{Au} / \mathrm{cm}^{2}\right)$ and lead ( $100 \mathrm{\mu g} / \mathrm{cm}^{2}$ ) on highly porous carbon felt provided inexpensive, efficient and practical electrodes that offer advantages of each metal without its disadvantages.

2. Characterization of different carbon felt materials revealed signiticant variations in their physical and surface chemical properties as well as their electrochemical behavior. As a result, the major cause for improper catalyzation was identified to be non-uniformity of the vendor supplied felts.

3. As a result of this program, catalyzation techniques were developed that were found to overcome most variations in the felt. A nitric acid soak as a normalization sreatment for carbon showed significant improvements. Subsequently, schematically shown in Figure VIII-i, the improved catalyzation technique, the alcohol assisted gold impregnation combined with a $\mathrm{KOH}$ precleaning step, produced electrodes which do not evolve measurable amounts of hydrogen and show excellent activity for the chromium redox reaction. An important aspect of this method of preparation is that it produces we" behaved electrodes from most lots of felts tried, so that characterization of the falt is no longer a major problen. These procedures seem entirely satisfactory for small cells and large single cells. Further refinements will be needed, however, to achieve second order improvements such as to minimize the blue hysteresis effects.

4. Differences observed in the cyclic voltarmetry scans can be correlated with the behavior of laboratory cells at MASA-LeRC. Because of the high internal surface area of the felt and the high internal resistance, experimental procedures must be standardized in order to make meaningful comnarisons. Pased on the cyclic voltammetric analysis rules of . on, gold and lead were identified and are summarized in Table VIII-I.

5. A technical grade chromic chloride solution was found acceptable in the short tern tests, but upon repeated cycling degradation was observed. He believe 
.1

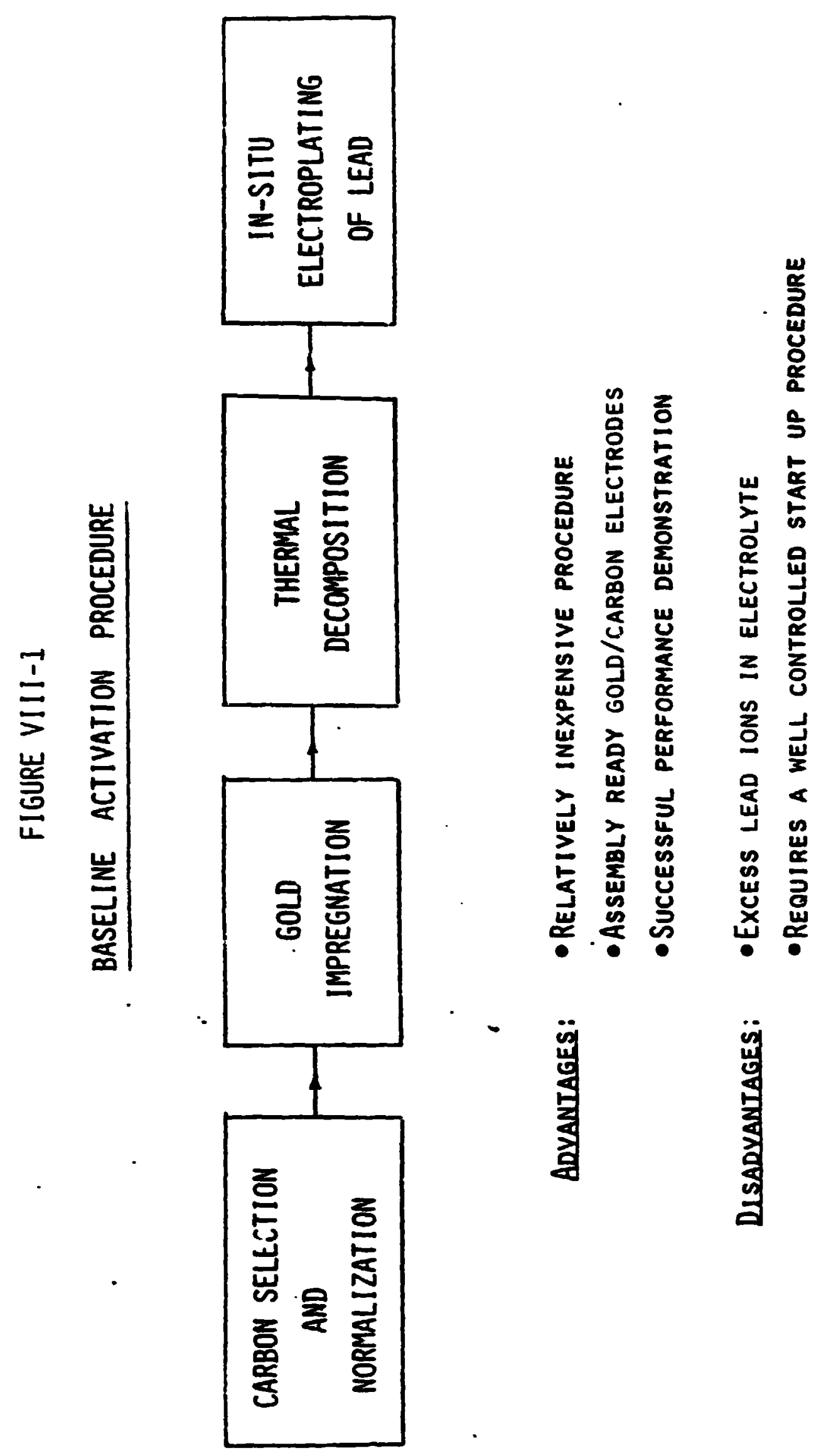




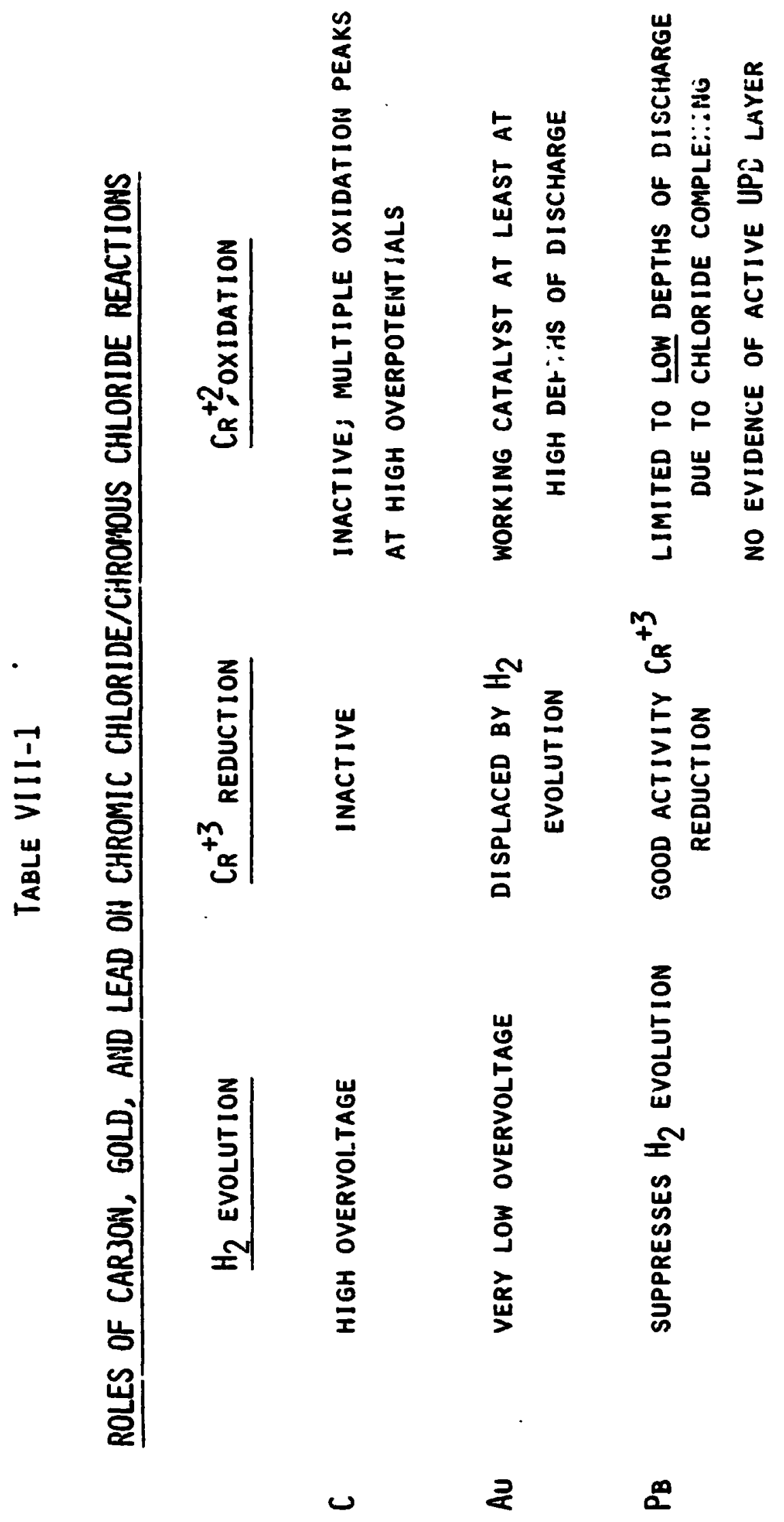


that impurities, yet to be identified, are the cause. It is concluded, at least during this stage of development, reagent grade chromic chloride should be used.

6. Based on exploratory observations, bismuth was found to be stable and to have activity for $\mathrm{Cr}$ (III)/Cr(II) redox reaction. Further work is necessary to determir.e its suitability for the redox battery.

The following are some observations made during the course of this study; definite conclusions with respect to these observations are beyond the present scope of the data and must await further data accumulation on more and different types of catalysts and electrodes.

1. An electrode after an exposure to chromium solution exhibited higher hydrogen evolution currents than it did before such an exposure. Does chromium adsorbed on carbon (or gold) surface enhance hydrogen evolution?

2. Frequently, but not consistently, lead deplating from bare carbon (or gold on carbon felt) showed two (or more) anodic peaks. This could be explained by either (a) deplating of two crystalline forms of lead or (b) deplating from two "types" of substrate surfaces, that is, inhomogeneous nature $r_{i}$ carbon surface.

3. Again, frequently, but not consistently, the onset of lead deposition occurred at less negative potentials on gold activated $c$ mon felt than for the bare carbon felt. We believe this along with a corresponding nge in the deplating tail to be evidence of preferential lead deposition on gold and higher stability of lead on the gold surface than on the carbon surface.

4. A?though the sensitivity of our instrumentation could measure submonolayer amounts of lead, we found no evidence of underpotential deposition (UPD) of lead either on carbon or on gold. In HCl mecium, lead complexes with chloride ions and perhaps does not undergo UPO. 
5. Under the lead loading conditions investigated, it appears that $\mathrm{Cr}$ (III) reduction depends on the amount of lead plated which, under the identical deposition conditions, varied with the type of felt or gold deposition procedure used.

6. Cyclic voltarmetry in a solution containing predominantly $\mathrm{Cr}\left(\mathrm{H}_{2} \mathrm{O}\right)_{6}^{+3}$ gave very little reactivity on lead on carbon surface. The similar test in a solution containing predominantly $\mathrm{Cr}\left(\mathrm{H}_{2} \mathrm{O}_{5} \mathrm{Cl}^{+2}\right.$ gave, on the first cycle, very good reactivity which steadily decreesed on subsequent rapid cycling, approaching the poor performance of the $\mathrm{Cr}\left(\mathrm{H}_{2} \mathrm{O}\right)_{6}^{+3}$. It is suggested that under the cycling conditions used, the reactive species, $\mathrm{Cr}\left(\mathrm{H}_{2} \mathrm{O}\right)_{5} \mathrm{Cl}^{+2}$, within the felt was gradually converted to the inactive species, $\mathrm{Cr}\left(\mathrm{H}_{2} \mathrm{O}\right)_{6}^{+3}$. This interconversion may play some role in a practical battery, but not to this extent. 
IX. RECOMME:IOATIONS FOR FUTURE WORK:

1. A comparison of the old carbon felt and graphite felt showed that the old carbon felt that had consistently given good electrodes which behaved very much like a graphite felt; their physical characteristics, surface chemistry as measured by pH of the soaking water (Table V-1) and electrochemical behavior (Figure V-5) were very similar. From these results it is reasonable to postulate that the NASA old carbon felt might have seen higher processing temperature and, therefore, be a little more graphitic in nature. Discussions with Fiber Materials, Inc. (17), further confirm this possibility; these felts are produced for insulation purposes and a close control on processing temperature is neither required nor maintained. Although preliminary investigations by $x$-ray diffraction (XRD) at NASA-LERC did not show any significant differences between the good and bad carbon felts, high resolution XRD analysis may bring out systematic differences in the interlayer spacings (18) and the degree of graphitization. We recomend i ivestigating effects of the felt processing temperature on the electrode behavior to establish the most desirable processing temperature.

2. It was demonstrated that trace amounts of gold and lead deposited on carbon felt provided efficient and practical electrodes. Preliminary investigations revealed, for example, that too little $\left(\leqslant 5 \mathrm{\mu g} \mathrm{Au} / \mathrm{cm}^{2}\right)$ and too much $\left(>60 \mu \mathrm{g} \mathrm{Au} / \mathrm{cm}^{2}\right) \mathrm{gold}$ yielded poor electrodes. Effects of various gold and lead loadings need further investigation to define the optimum quantities of lead and gold necessary to suppress hydrngen evolution and to maximize $\mathrm{Cr}$ (III)/Cr(II) redox reaction.

3. Although the alcohol assisted catalyzati ull procedure seems satisfactory, further refinements are recommended to achieve (a) better distribution of highiy dispersed gold particles and (b) other second order systen improvements such as to minimize the open circuit hysteresis and discharge voltage dip that are believed to be caused by the different complexes of $\mathrm{Cr}$ (III).

4. Investigations of multiple peaks on the oxidation portion of cyclic voltammetry and electrochemistry of chloride complexes of $\mathrm{Cr}(I I I)$ also deserve further 
attention and should contribute towards optimization of the chromium electrodes.

5. We further recomend that investigations be continued to search for newer electrocatalysts and catalyzation techniquss which may provide further improvements in the chronium electrodes and increase the commercial viability of iron chromium redox flow systems for bulk energy storage applications.

6. Finally, it would be highly desirable to develop a cost effective manufacturing technology to fabricate the electrodes for the iron/chromium redox cells as items of commerce; that is, an ability to deliver "assenbly ready" electrodes to commercial cell developers. 


\section{REFERENCES}

1. L.H. ihaller, "Recent Advances in Redox Flow Cell Storage Systems," Dept. of Energy, Washington, D.C., DOE/NASA/1002-79/4, National Aeronautics and Space Adnin., Wasnington, D.C., NASA TM-79186 (1979).

2. L.H. Thaller, "Redox Flow Cell Energy Storage Systems," Dept. of Energy, Washington, D.C., DOE/NASA/100:-79/3, National Aeronautics and Space Admin., Washington, D.C., NASA TM-79143 (1979).

3. J. Giner, L. Swette and K. Cahili, "Screening of Redox Couples and Electrode Materials," NASA-Lewis Research Center, Cleveland, OH, Contract No. NAS319760, NASA CR-134705 (1976).

4. J. Giner and K. Cahill, "Advanced Screening of Electrode Couples," Giner, Inc., Waltham, MA, Dept. of Eriergy, Wasinington, D.C., DOE/NASA/0794-80/1, National Aeronautics and Space Admin., Washington, D.C., NASA CR-159738 (1979).

5. 3. Giner and K. Cahill, "Catalyst Surfaces for the Chromous/ Chromic Redox Couple," U.S. Patent No. 4,192,910, March 11, 1980.

6. V. Jalan, K. Cahill, D. Dethuth and J. Giner, "Electrocataivsts for the $\mathrm{Cr}^{+3} / \mathrm{Cr}^{+2}$ Redox Couple," Extended Abstracts, 157th Spring Meeting of Electrochenical Society, St. Louis, Missouri, Maj 11-16, 1980, Vol. 80-1, Paper No. 351, pp. 874-6.

7. b. Jalan and H. Stark, "Gold-Lead Catalysts for $\mathrm{Cr}^{+3} / \mathrm{Cr}^{+2}$ Redox Reactions" Extended Abstracts, Electrochemical Society Meeting, Hollywood, Florida, October 1980, Vol. 80-2, Paper No. 150, pp. 410-2.

8. H. Lux and J. Illman, "Zur Ke-ntis der Chrom (iI) - Salze und des Chrom (II) oxyds, I," Chen. Ber., 91, 2143 (1958).

9. R. Gahn, NASA-Lewis Research Center, Cleveland, $\mathrm{OH}$, Personal Communications.

10. M.A. Reid, NASA-Lewis Research Center, Cleveland, OH, Personal Communicatior.s.

11. V. Jalan, M. Reid and J. Charleston, U.S. Patent Applied, Patent Application No. 352,821 (February 1982). 
12. M.A. Reid and L.H. Thaller, "Improvement and Scale-up of the N.ASA Redox Storage System," NASA Lewis Research Center, Cleveland, $\mathrm{OH}$, Dept. of Energy, Washington, D.C., DOE/NASA/12726-6, National Aeronautics and Space Admin., Washington, D.C., NASA TM-81632, in paper prepared for the 15th IECEC, Seattle, WA, August 1980.

13. R.R. Adzic, M.D. Spasojevic and A.R. Despic, "Hydrogen Evolution on tiola Electrode In The Presence of Lead Adatoms," Electrochemica Acta, 24, 577-9 (1979).

14. J.D.E. McIntyre and W.F. Peck, "Electrochemical Catalysis by Foreign Metal Adatoms," Proc. Third Symp. Electrode Processes, 1979, p. 322-49.

15. S.S. Donovan and E. Yeager, "The Electrode Kinetics of the ChromousChromic Couple," Office of Naval Research, Contract N00014-67-C-1389, p. 6 (1969).

16. M. Pourbaix, "Atlas d'Equilibres Electrochemiques à $25^{\circ} \mathrm{C}$," GauthierVillars, Paris (1963).

17. H. Dietrich and D. Hodsdon, Fiber Materials, Inc., Biddeford, ME, Personal Conmunications.

18. A. Pacault, "The Kinetics of Graphitization," in Chemistry and Fhysics of Carton, (P.1. Walker, Jr., ed.) Vol. 7, Dekker, New York (1971). 


\section{APPENDIX A}

\section{STANDARD THERMAL GOLD PLATING METHOD}

1. Heat $14.5 \mathrm{~cm}^{2}$ projected area sample of carbon felt in concentrated $\mathrm{H}_{2} \mathrm{SO}_{4}$ for 30 minutes $\mathrm{a} 100^{\circ} \mathrm{C}$.

2. Rinse with distilled water and damp dry.

3. Soak in $1.25 \times 10^{-3} \mathrm{~m} \mathrm{Au}^{3+}$ solution overnight.

4. Drain on paper towel for about 30 minutes.

5. Dry in $70^{\circ}$ to $80^{\circ} \mathrm{C}$ oven. Turn each hour for 3 hours.

6. Heat in furnace for 2 hours at $260^{\circ} \mathrm{C}$. 


\section{ALCOHOL ASSISTED GOLD DEPOSITION METHOO FOR MAKING FELT ELECTROOES}

Major causes for poor performing gold/lead on felt electrodes are non-unifort gold take up and uneven distribution of gold. It is believed that "as received" carbon felts have localized reactive and hydrophobic regions. Improved electrodes were made by precleaning carbon felts and the use of alcohol to help gold solution to uniformily wet the carbon surface. The procedure given below resultied from joint efforts by Giner, Inc. and NASA-LeRC. Al though evolutionary and not necessarily optimum, this process has yielded the best performing electrodes to aate.

Square $14.5 \mathrm{~cm}^{2}$ samples were cut from carbon felt obtained from the mani.facturer and soaked in methyl alcohol for 30 minutes, rinsed in tap water and damp dried with laboratory wipes. The felt is cleaned by heating in $45 \% \mathrm{KOH}$ (approximately) at $100^{\circ} \mathrm{C}$ for two hours.

The felt is rinsed successively in tap and deionized water, and then soaked in deionized water overnight. The felt is damp dried and moistened evenly with $0.22 \mathrm{cc} / \mathrm{cm}^{2}$ of electrode of a $25 \% \mathrm{H}_{2} 0-75 \%$ methanol solution containing $62.5 \mathrm{\mu g} / \mathrm{ml}$ of $\mathrm{HAuCl}_{3} \cdot 3 \mathrm{H}_{\mathrm{c}} \mathrm{O}$. The felt is allowed to stand overnight in contact with this solution in the dark. It is then dried in an oven at $100^{\circ} \mathrm{C}$ for $2-3$ hours, heated for $2 \frac{3}{2}$ hours at $260^{\circ} \mathrm{C}-270^{\circ} \mathrm{C}$ in the furnace, wetted with $2 \mathrm{H} \mathrm{HCl}$, and placed in a redox cell.

We believe that cleaning felts with hot concentrated $\mathrm{KOH}$ will "normalize" the felts by oxidizing the excess reducing groups. Alcohol plays two roles to provide uniform and fine distribution. First, because it wets carbon (or graphite) surface very well, it makes the entire surface available for gold deposition. Second, alcohols (methanol, ethanol and ispropanol) are known to reduce acidic solutions of gold chloride to produce very fine particles of colloidal sold that would adsorb immediately on the surface of the carbon substrate. Such a deposition provides spatially uniform distribution of highiy dispersed gold particles which are not affected by the drying process. 
Before oven drying, it has been a present practice to press the felt electrode with a flat glass object to distribute the gold solution uniformly over the electrode. We recomend that a preferred method to assist uniform distribution of the gold solution on the electrode woulu be to subject gold solution soaked electrodes to ultrasonic vibrations. This can easily be achieved by, for example, placing a pyrex plate, with gold solution soaked felt, in an ultrasonic cleaner for short times. 